\title{
Plasma polymerization of cyclopropylamine in a low-pressure cylindrical magnetron reactor: a PIC- MC study of the roles of ions and radicals
}

\author{
Stella Mathioudaki, ${ }^{1}$ Cédric R. Vandenabeele, ${ }^{1}$ Romain Tonneau, ${ }^{1}$ Andreas Pflug, ${ }^{2}$ Jonathan \\ Tennyson, ${ }^{3}$ and Stéphane Lucas. ${ }^{1, a)}$
}

\begin{abstract}
${ }^{1}$ Laboratory of Analysis by Nuclear Reaction, Namur Institute of Structured Matter, University of Namur, Rue de Bruxelles 61, 5000, Namur, Belgium

${ }^{2}$ Fraunhofer Institute for Surface Engineering and Thin Films IST, Bienroder Weg 54e, 38108 Braunschweig, Germany

${ }^{3}$ Department of Physics and Astronomy, University College London, Gower Street, London WC1E 6BT, UK

a)Corresponding author: Stéphane Lucas, Tel: +32 (0)81 7254 81; e-mail address: stephane.lucas@unamur.be
\end{abstract}

A study of the plasma polymerization of cyclopropylamine in a low-pressure cylindrical magnetron reactor is presented. Both experimental and numerical approaches are used to investigate the thin film growth mechanisms and polymer film properties depending on the magnetic field strength. Combining both approaches enables to check the consistency of the numerical model while acquiring data for understanding the observed phenomena. Samples are first analyzed by X-ray Photoelectron Spectroscopy, Time of Flight Secondary Ion Mass Spectrometry and Ion Beam Analysis to illustrate the differences in degrees of chemical functionalization and cross-linking between the regions of high and low magnetic field. 3D Particle-In-Cell Monte Carlo collision simulations are then performed to shed light on experimental results, after implementing a set of electron-cyclopropylamine collision cross sections computed using the R-matrix method. The simulations enable to track the main radicals produced in the discharge, by determining their production rates, how they diffuse in the plasma and how they absorb on the reactor walls. Additionally, the cyclopropylamine ion 
$\left(\mathrm{C}_{3} \mathrm{H}_{7} \mathrm{~N}^{+}\right)$behavior is followed to bring insights into the respective roles of ions and radicals during the plasma polymerization process.

\section{INTRODUCTION}

During the last years, amine-rich surfaces have gained increasing interest for a number of applications, including wastewater purification membranes, ${ }^{1}$ cell colonization, ${ }^{2}$ or biomolecule immobilization. ${ }^{3}$ A convenient way to prepare such surfaces is to deposit a thin organic layer by plasma polymerization, which enables to tune the surface properties with a high level of control by a judicious choice of the precursor molecule and plasma parameters. ${ }^{4}$ Synthesis of amine-based plasma polymer films (PPFs) is mainly focused on two features that usually follow opposite trends: the incorporation of a high content of primary amine groups $\left(\mathrm{NH}_{2}\right)$ and the obtaining of a stable coating in aqueous solvents. ${ }^{5,6}$ Optimizing PPF properties is based on a good knowledge of the thin film growth mechanisms.

Plasma polymerization relies on the activation of a precursor molecule in the plasma phase through collisional processes with energetic electrons and subsequent condensation of activated species on a surface. ${ }^{4,7}$ In low pressure plasmas, electrons are characterized by an electron energy distribution function (EEDF), whose most probable value is centered around $1-2 \mathrm{eV} \cdot{ }^{8-10}$ Thus, most of the electrons have an energy closer to dissociation energies of organic bonds $(2-5 \mathrm{eV})$ than to ionization energies $(>10 \mathrm{eV})$. This, in combination with the longer residual time of radicals, implies that the concentration of radicals in an organic discharge can be $10^{3}-10^{5}$ times higher than the concentration of positive ions. ${ }^{11}$ For this reason, it was historically assumed that the growth of a PPF in plasma deposition processes is mainly governed by radical-surface interactions, as summarized in the "Rapid Step Growth Polymerization" (RSGP) mechanism of Yasuda. ${ }^{12}$

Initially, ions were mainly supposed to induce chemical bond breaking after impacting the growing film surface, leading to the creation of preferential adsorption sites for reactive 
species and unsaturated molecules, and promoting the PPF cross-linking. This phenomenon, described in the "ion-Activated Growth Model" of d'Agostino, ${ }^{13}$ still implies that the ion density in the plasma is too low to contribute significantly to the mass deposited. However, more recent studies brought experimental evidence that ions can play an important role in the deposition mechanisms, and even be the main species responsible for PPF growth. ${ }^{14,15}$

Different reasons are given to explain this observation. First, ions are accelerated in the sheath that naturally develops around any floating surface immersed in a plasma, which considerably reduces to $10^{2}-10^{3}$ the neutral/ion flux ratio directed toward the surface (flux being defined by density times velocity). ${ }^{16}$ Second, due to this acceleration, ions arrive at the surface at much higher energy (15-20 eV for a floating surface) than neutrals (including radicals and intact precursor molecules, $0.03-0.05 \mathrm{eV}$ ), which confers to ions a much richer chemistry and generally higher sticking probabilities $(0.2-1)$ compared with neutrals $\left(10^{-4}-\right.$ 1). ${ }^{7,17}$ Let us note that ions can have an even greater energy if the surface is polarized with high negative voltage. Third, experimental studies have revealed the formation in the gas phase of heavy ionic oligomers of the form $(n \mathrm{M}+\mathrm{H})^{+}$(with $\mathrm{M}$ the precursor molecule and $n$ an integer as high as 3 to 4$),{ }^{18,19}$ which can be incorporated in the PPF and contribute to the deposited mass. $^{16}$

Michelmore et al. showed that the PPF deposition mechanisms, and ultimately the final layer properties, mainly depends on the monomer structure and the power injected into the discharge. Indeed, plasma polymerization from saturated monomers is dominated by ionic deposition, while deposition from unsaturated monomers at low power is dominated by grafting of neutral species on surface dangling bonds generated by ion impacts. ${ }^{20}$ Increasing the power delivered to unsaturated monomer discharges increases the contribution of ionic deposition due to the fragmentation of multiple bonds moieties and higher ion/neutral flux ratio. These authors showed that films grown predominantly from neutral deposition (i.e., saturated monomer at 
low power) are generally denser but less cross-linked and more soluble. Nevertheless, as shown by Hegemann et al. in the case of ethylene-based coatings, the PPF density increases with ion energy beyond a certain threshold due to the hydrogen abstraction that occurs and leads to more cross-linked and harder coatings. ${ }^{21}$

To summarize, even if the importance of ions in the PPF growth mechanisms has been clearly demonstrated, the relative contributions of ions and radicals is still debated today. Up to now, these contributions have mainly been investigated by experimental techniques such as ion probes and mass spectrometry. ${ }^{7}$ In the present work, we study with a numerical tool the respective roles of ions and radicals in a plasma polymerization process performed in a particular reactor geometry. The reactor is a home-made cylindrical magnetron reactor that was designed for the surface modification of powders and has already been used for the functionalization of carbon nanotubes ${ }^{22}$ and metal oxide nanoparticles. ${ }^{23}$ The precursor chosen is cyclopropylamine $\left(\mathrm{CPA}, \mathrm{C}_{3} \mathrm{H}_{7} \mathrm{~N}\right)$, which is a non-toxic isomer of the highly studied allylamine molecule, and which has recently shown a great potential to deposit stable PPFs with high content of primary amine groups. ${ }^{24-33}$

Plasma modelling is extensively used to help understanding of plasma processes, to predict final coatings properties, to optimize plasma chambers and to ease the scaling-up of a process. ${ }^{34,35}$ Nevertheless, plasma simulations of organic discharges are limited to molecules with a low number of atoms and only include simple reactions due to the lack of cross sections and rate coefficient. ${ }^{36}$ The most studied molecule is acetylene $\left(\mathrm{C}_{2} \mathrm{H}_{2}\right)$ that has been investigated alone ${ }^{37-40}$ or in combination with $\mathrm{Ar},{ }^{41} \mathrm{Ar}$ and $\mathrm{H}_{2},{ }^{42}$ and $\mathrm{NH}_{3} .{ }^{17}$ Other molecular systems studied by plasma simulation include $\mathrm{CF}_{4},{ }^{43,44} \mathrm{CF}_{4} / \mathrm{O}_{2},{ }^{45} \mathrm{CH}_{4},{ }^{46} \mathrm{CH}_{4} / \mathrm{O}_{2}{ }^{47} \mathrm{CH}_{4} / \mathrm{C}_{2} \mathrm{H}_{2},{ }^{17}$ or $\mathrm{C}_{4} \mathrm{~F}_{8}{ }^{48}$ To date, no plasma modelling study of the CPA molecule has been yet reported.

Depending on their conditions, plasmas can be either modelled using fluid dynamics or kinetic approaches. ${ }^{49,50}$ In fluid dynamics, equations of continuity, drift, diffusion and energy 
flux are solved self-consistently with a reduced Maxwell equation for the electric potential. It is necessary to use certain assumptions for the energy distribution functions of the involved species. In the discharge geometry investigated here, a substantial part of plasma reactions and nanoparticle surface treatment is expected to happen within the plasma sheath and therefore, no equilibrium assumption of the local velocity distribution would hold. A proper description of this zone requires to apply kinetic methods such as the Particle-in-Cell Monte-Carlo (PICMC) method, which statistically solves the Boltzman equation including collision term. ${ }^{51}$ Its most crucial numerical constraint is the spatial resolution of electric potential fluctuations; for numerical stability, an upper limit of the cell size proportional to the Debye length is required. ${ }^{52}$ This considerably limits the maximum plasma density, which can be modelled with feasible effort. Similarly, the transport of neutral particles can be either modelled by computational fluid dynamics (CFD) or by kinetic methods such as the Direct Simulation Monte Carlo (DSMC) - method. ${ }^{53}$ The crucial criterion for the maximum tolerable cell size in the DSMC method is the mean free path, which implies a strong scaling of its numerical effort with total pressure. The advantage of the DSMC method is that it enables a direct description of particle transport and particle-wall interactions even under non-thermal conditions, while in CFD models several assumptions, like local diffusion coefficients, viscosity, turbulence models, etc., are required. For the investigations in this paper a parallelized, combined DSMC / PIC-MC implementation, described in reference ${ }^{54}$, is used. 3D PIC-MC simulations of a low pressure Ar discharge have already been reported in our cylindrical magnetron reactor. ${ }^{55}$ The model has been shown to be a powerful tool to visualize and understand the influences of the magnetic field and the excitation mode on particles motion and plasma parameters.

The article is organized in two parts. In the first part, CPA-based PPFs are deposited onto $\mathrm{Si}$ wafers at two different locations where the magnetic field strength strongly differs, namely, where plasma species densities and energies are different. The samples are analyzed 
by profilometry, X-ray Photoelectron Spectroscopy (XPS), Time-of-Flight Secondary Ion Mass Spectroscopy (TOF-SIMS) combined with Principal Component Analysis (PCA) and Ion Beam Analysis (IBA), to determine the influence of the magnetic field strength on the degrees of functionalization and cross-linking of the plasma layers. In the second part, after calculating electron impact cross sections of CPA through the R-matrix method, ${ }^{56}$ two runs of 3D PIC-MC simulations are performed at different levels of detail to track the behaviors of CPA ions and of the main radicals produced in the discharge. The simulations aim to bring new insights on how the different plasma species intervene in the plasma polymerization mechanisms and influence the resulting PPF properties.

\section{EXPERIMENTAL SET-UP}

The plasma reactor has been extensively described in previous studies, ${ }^{22,23,55}$ which are summarized in the recent review of Vandenabeele and Lucas. ${ }^{57}$ In summary, the reactor consists of a cylindrical drum maintained on a grounded iron support, which contains a block of magnets. Gases are supplied through a gas shower located along the drum axis. Drum and gas shower are the electrodes of the system, made of stainless steel, electrically insulated from the rest of the setup, and connected to the poles of the power supply. The power supply operates in pulsed bipolar mode, as described in reference ${ }^{55}$, except that off-times are $25 \mu$ s instead of $10 \mu$ s on each polarity. More precisely, each electrode is alternatively the cathode and the anode of the system. For each polarity, the power is applied during $10 \mu$ s (on-time), followed by 25 $\mu$ s of off-time. The mean power dissipated in the discharge is $24 \mathrm{~W}$ (for both treatment and

pretreatment), as calculated according to the method described in reference ${ }^{55}$. The working pressure in the chamber is fixed at $10 \mathrm{~Pa}$.

PPFs are deposited onto $1 \times 1 \mathrm{~cm}^{2}$ pieces of Si wafers (Sil'tronix) that are placed at diametrically opposite positions in the middle of the drum, as shown in Fig. 1. Sample A is 
located at the bottom of the reactor, where the magnetic field strength has the highest value $(\sim 150 \mathrm{mT})$, while sample B is located at the top of the reactor, where the magnetic field is two orders of magnitude lower $(\sim 1.5 \mathrm{mT}) .{ }^{55}$ Initially, Si wafers are cleaned for 5 minutes in an $\mathrm{Ar}$ discharge with an Ar flow rate of 30 standard cubic centimeters per minute $(\mathrm{sccm})$ and a discharge power of $20 \mathrm{~W}$ using the same pulse scheme as described above. Subsequently, after evacuating Ar from the chamber, the deposition is carried out in pure CPA (98\%, Sigma Aldrich, $15 \mathrm{sccm}$ ) during $16 \mathrm{~min}$.

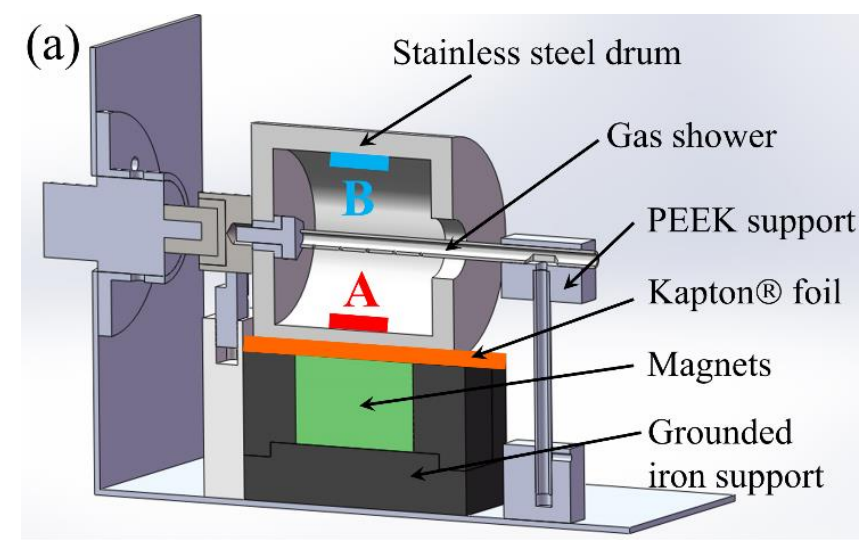

(b)

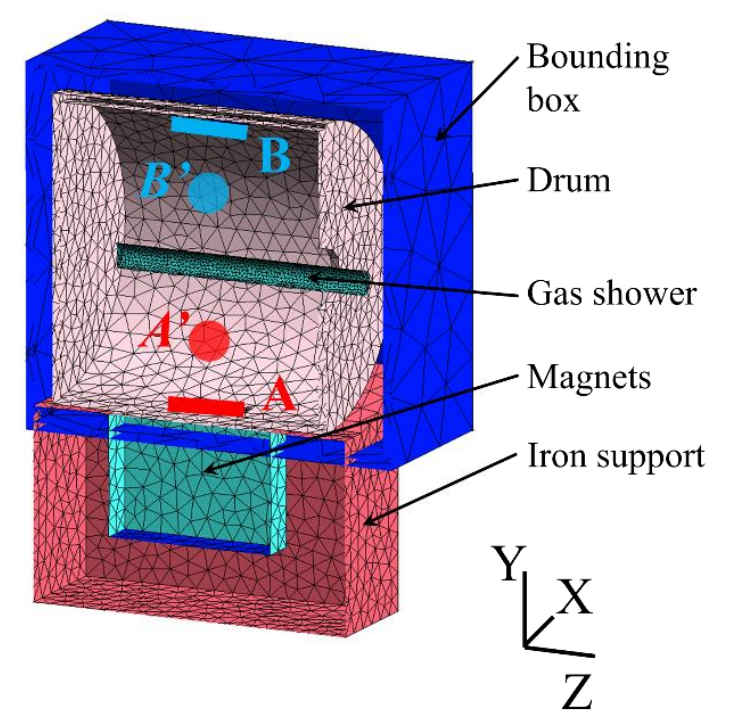

FIG. 1. (a) Scheme of the experimental set-up used for the deposition of PPFs, showing the two positions where PPFs have been analyzed. (b) Mesh geometry of the plasma reactor used for 
the PIC-MC simulations. $A$ ' and $B^{\prime}$ are $1 \mathrm{~cm}$ in diameter virtual spherical volumes where local densities have been numerically assessed.

The samples are first analyzed by profilometry and Scanning Electron Microscopy (SEM) to measure the deposition rates and observe the PPF morphology at the two positions A and B. Then, XPS analyses are performed to measure the elemental composition and get a hint of the different chemical groups grafted into the PPFs. Next, TOF-SIMS analyses combined with PCA treatment are performed to observe the main chemical differences between both samples, particularly in terms of degrees of functionalization and cross-linking. Finally, IBA is used as a complementary tool, mainly to quantify the hydrogen content in the layers and confirm PCA results.

Deposition rates are measured by profilometry using a Dektak Veeco 8 stylus device, and also estimated from SEM cross-sectional views by using a JEOL 6010LV microscope. XPS analyses are carried with a ThermoFisher K-Alpha photoelectron spectrometer (monochromatized $\mathrm{Al} \mathrm{K}_{\alpha}$ photon source, $1486.6 \mathrm{eV}$ ). Survey and high resolution spectra are recorded at pass energies of $200 \mathrm{eV}$ and $30 \mathrm{eV}$, respectively, using a $250 \mu \mathrm{m}$ in diameter $\mathrm{X}$ rays spot. High resolution spectra are fitted with Lorentzian-Gaussian components (L/G = $30 \%$ ), with a full width at half maximum (FWHM) between 1.8 and $2.0 \mathrm{eV}$.

TOF-SIMS spectra are acquired by using a TOF-SIMS IV (Ion-Tof GmbH, Münster, Germany) spectrometer in the positive mode by using a $\mathrm{Bi}_{3}{ }^{+}$beam with a current of $0.35 \mu \mathrm{A}$ at $25 \mathrm{keV}$, which is rastered over a $200 \times 200 \mu \mathrm{m}^{2}$ area. A low energy flood gun is used to ensure charge compensation and at least 5 points are analyzed for each sample. The calibration is done on $\mathrm{CH}^{+}, \mathrm{CH}_{3}{ }^{+}$and $\mathrm{C}_{2} \mathrm{H}_{2}{ }^{+}$peaks. After normalizing the peak intensities with respect to the total secondary ion count, the interpretation of TOF-SIMS spectra is done through the Principal Component Analysis (PCA) method by using the NESAC/BIO Toolbox (Spectragui). ${ }^{58}$ 
To give some details about this method, PCA is a statistical method that allows to assess the main differences contained in a large amount of data. As well summarized by Cossement et al., ${ }^{5}$ PCA can be viewed as a projection method that turns an initial set of observations (e.g.: TOF-SIMS spectra) of a $n$-dimensional system ( $n$ being the number of TOF-SIMS peaks considered) into a highly lowered dimensional system ( 2 or 3 dimensions). The principal components $\left(\mathrm{PC}_{\mathrm{i}}\right)$ are the axes of the new system and their direction is calculated to display the maximum variance of the initial $n$-dimensional system. The PCA approach decomposes the initial system into a set of scores and loadings. The scores are the new coordinates of the observations (TOF-SIMS spectra) and correspond to the projection of the initial coordinates (intensities of the TOF-SIMS peaks considered) onto the different $\mathrm{PC}_{\mathrm{i}}$. The loadings give the statistical weight of contribution of the TOF-SIMS peaks to the $\mathrm{PC}_{\mathrm{i}}$. In this way, PCA analysis gives an overview, classification and discrimination of the samples, as well as their chemical characterization. The reader can find a more detailed description of the PCA technique in references ${ }^{59,60}$.

IBA analyses are performed by combining Elastic (non-Rutherford) Backscattering Spectroscopy (EBS) and Elastic Recoil Detection Analysis (ERDA). The analysis is done by using a $2.1 \mathrm{MeV}^{4} \mathrm{He}$ beam with an intensity of about $3 \mathrm{nA}$. The sample under analysis is tilted at $65^{\circ}$ relative to the incident beam direction such that the irradiated area is about $2.5 \times 1.0$ $\mathrm{mm}^{2}$. Data are recorded from three Passivated Implanted Planar Silicon (PIPS) detectors set at $165^{\circ}$ and $135^{\circ}$ (EBS-detectors), and $30^{\circ}$ (ERDA-detector) with respect to the incident beam direction. The energy calibration of EBS-detectors is achieved from $\mathrm{SnO}_{2} / \mathrm{SiO}_{2}$ standard sample analysis, while the ratio between the ERDA and EBS detectors is derived from the analysis of a Kapton foil. The elemental depth profiles are obtained by fitting the ERDA and EBS spectra using DataFurnace ${ }^{61}$ with the cross sections generated by SigmaCalc. ${ }^{62}$ 


\section{SIMULATION MODEL SET-UP}

\section{A. Cross section calculations}

We are unaware of previous electron collision cross sections for the CPA molecules. Therefore, to provide collision data for the PIC-MC simulations, collision cross sections between electrons and CPA molecules are computed via a combination of the Binary Encounter Bethe (BEB) and ab-initio R-matrix methods by Quantemol Ltd. There are more electronimpact processes involving polyatomic molecules (like CPA) than those calculated here. In particular, electron impact vibrational excitation was not considered as such calculations on a system like CPA are not technically possible at present. Cross sections are calculated for the following electron-CPA collision processes:

Ionisation:

$\mathrm{C}_{3} \mathrm{H}_{5} \mathrm{NH}_{2}+e^{-} \rightarrow \mathrm{C}_{3} \mathrm{H}_{5} \mathrm{NH}_{2}^{+}+2 e^{-}$

Dissociative ionisation:

$\mathrm{C}_{3} \mathrm{H}_{5} \mathrm{NH}_{2}+e^{-} \rightarrow \mathrm{C}_{3} \mathrm{H}_{5} \mathrm{NH}_{2}^{-} \rightarrow \mathrm{C}_{a} \mathrm{H}_{b} \mathrm{~N}_{c}^{+}+\mathrm{C}_{n} \mathrm{H}_{m} \mathrm{~N}_{p}+2 e^{-}$

Electronic excitation:

$\mathrm{C}_{3} \mathrm{H}_{5} \mathrm{NH}_{2}+e^{-} \rightarrow \mathrm{C}_{3} \mathrm{H}_{5} \mathrm{NH}_{2}^{*}+e^{-}$

Rotational excitation:

$\mathrm{C}_{3} \mathrm{H}_{5} \mathrm{NH}_{2}(\mathrm{~J}=0)+e^{-} \rightarrow \mathrm{C}_{3} \mathrm{H}_{5} \mathrm{NH}_{2}(\mathrm{~J})+e^{-}$

where $a+n=3, b+m=7$ and $c+p=1$.

The total electron-CPA ionization cross section is calculated using ab initio Binary Encounter Bethe (BEB) method, ${ }^{63}$ which is a combination of Mott ${ }^{64}$ and Bethe ${ }^{65}$ theories. Those theories describe respectively the hard, close collisions with small impact parameters, and the soft collisions with large input parameters. The BEB method accounts for both collision types and the BEB total ionisation cross section is calculated according to:

$\sigma_{B E B}=\frac{S}{t+u+1}\left(\frac{1}{2}\left(1-\frac{1}{t^{2}}\right) \ln (t)+1-\frac{1}{t}-\frac{\ln (t)}{t+1}\right)$ 
where $t=\frac{T}{B}, u=\frac{U}{B}$ and $S=4 \pi a_{0}^{2} N\left(\frac{R}{B}\right)^{2} . T$ is the kinetic energy of the incident electron, $B$ and $U$ are the binding energy and average kinetic energy of the electrons in a sub shell, $N$ is the number of bound electrons, $R$ is the Rydberg constant and $a_{0}$ the Bohr radius. Electron kinetic and binding energies of orbitals in the CPA molecule are calculated using the MOLPRO quantum chemistry software based on the Hartree-Fock approximation. ${ }^{66} \mathrm{BEB}$ cross sections have proved to be reliable for small organic molecules. ${ }^{67,68}$

Dissociative ionization cross sections are calculated by adapting Eq. 1 as follows:

$\sigma_{f}=\frac{\Gamma_{f} S}{t_{f}+u+1}\left(\frac{1}{2}\left(1-\frac{1}{t_{f}^{2}}\right) \ln \left(t_{f}\right)+1-\frac{1}{t_{f}}-\frac{\ln \left(t_{f}\right)}{t_{f}+1}\right)$

where $\Gamma_{f}$ is the branching ratio of the species and $t_{f}=\frac{T}{B-D_{f}}$, with $D_{f}$ the energy threshold at which the fragment $f$ appears. Eq. (2) thus requires the knowledge of kinetic and binding energies of the incident and bound electrons, the energy thresholds at which each ionic fragment and their branching ratios. The energy threshold at which a dissociative ionization channel opens is equal to the ionization energy of the initial molecule plus the energy required to break all dissociating bonds minus the energy recovered by the formation of new bonds in the products. The energies considered for bond breaking or formation in the CPA dissociative channels are the binding energies found in the literature and are collected in Table 1 . The energy-dependent branching ratios of the different fragments are derived from the experimental cracking patterns of gaseous CPA measured by mass spectrometry for various values of electron energy (in the ionization source of the spectrometer), as described in reference ${ }^{69}$. This method has so far been tested only for the $\mathrm{NH}_{3}$ and $\mathrm{NF}_{3}$ molecules, for which it was found to work well. ${ }^{69}$

TABLE 1. Energies for bond-breaking in nitrocarbons.

Type of Bond $\quad$ Instance of Bond $\quad$ Bond Energy (eV) 


\begin{tabular}{lll}
\hline $\mathrm{C}-\mathrm{H}$ & $\mathrm{C}-\mathrm{H}$ & $3.513^{70,71}$ \\
& $\mathrm{HC}-\mathrm{H}$ & $4.371^{70-72}$ \\
& $\mathrm{H}_{2} \mathrm{C}-\mathrm{H}$ & $4.900^{70,71}$ \\
& $\mathrm{NCH}_{2} \mathrm{C}-\mathrm{H}$ & $3.426^{73}$ \\
& $\mathrm{NC}-\mathrm{H}$ & $5.594^{74}$ \\
$\mathrm{C}-\mathrm{C}$ & $\mathrm{H}_{3} \mathrm{C}-\mathrm{CN}$ & $5.247^{70,71}$ \\
& $\mathrm{CH}-\mathrm{CH} 3$ & $3.903^{75}$ \\
$\mathrm{C}-\mathrm{N}$ & $\mathrm{C}-\mathrm{N}$ & $7.589^{70,71}$ \\
& $\mathrm{H}_{3} \mathrm{C}-\mathrm{NH} 2$ & $3.426^{70,71}$ \\
& $\mathrm{H}_{5} \mathrm{C}_{3}-\mathrm{NH}_{2}$ & $3.118^{76}$ \\
$\mathrm{H}-\mathrm{H}$ & $\mathrm{H}-\mathrm{H}$ & $4.518^{70,71}$ \\
$\mathrm{~N}-\mathrm{H}$ & $\mathrm{N}-\mathrm{H}$ & $3.686^{70,71}$ \\
$\mathrm{C} \equiv \mathrm{C}$ & $\mathrm{HN}-\mathrm{H}$ & $3.903^{70,71}$ \\
\hline \hline & $\mathrm{HC} \equiv \mathrm{CN}-\mathrm{H}$ & $4.510^{70,71}$ \\
& $\mathrm{C}=\mathrm{N}$ & $6.374^{77,78}$ \\
& $\mathrm{C}=\mathrm{C}$ & $6.288^{79,80}$ \\
& $\mathrm{~N}$ & 70,71 \\
\hline
\end{tabular}

Calculation of the electronic excitation cross sections is performed by using R-matrix radii of $13 \mathrm{a}_{\mathrm{o}}$ and Gaussian Type Orbitals to represent the continuum extending up to $l=4$. Full description of the R-matrix method can be found in references ${ }^{56,81}$. Two different calculations that construct the inner region wavefunction are performed. The first is performed from orbitals computed by a Complete Active Space Consistent Field (CASSCF) calculation made using Program MOLPRO ${ }^{66}$ and the second is performed using Hartree-Fock (HF) orbitals calculated using the R-matrix electron-scattering Program UKRMol. ${ }^{82}$ The Quantemol-N expert system ${ }^{83}$ is used to run the UKRMol codes. The CASSCF wavefunctions freeze the [1-7 a',1-3 a"] orbitals, ${ }^{79}$ put the remaining electrons in the active space $\left[8-14 \mathrm{a}^{\prime}, 4-6 \mathrm{a}^{\prime \prime}\right]^{69}$ and explicitly include the ${ }^{1} \mathrm{~A}^{\prime}$ and ${ }^{3} \mathrm{~A}^{\prime}$ state configurations. Complete Active Space Configuration Interaction 
(CAS-CI) calculations ${ }^{53}$ are then made with these orbitals, constructed from $6-311 \mathrm{G}^{*}$ and ccpVTZ basis sets. Table 2 shows the calculated vertical excitation energies. Excitation cross sections leaving CPA in the first 4 excited states a ${ }^{3} \mathrm{~A}^{\prime}, \mathrm{A}^{1} \mathrm{~A}^{\prime}, \mathrm{b}^{3} \mathrm{~A}^{\prime}$ and $\mathrm{c}^{3} \mathrm{~A}^{\prime \prime}$ are taken from the calculation with orbitals constructed from a 6-311G* basis set and a CASSCF wavefunction. Inelastic cross sections to states with thresholds below the vertical ionization energy of $9.8 \mathrm{eV}$ are taken from the calculation with a $\mathrm{HF}$ wavefunction with orbitals constructed from a 6-311G* basis set for consistency. The calculation of the electronic excitation cross sections must be regarded as the most uncertain part of the computations presented here and the ones presented represent what is possible to obtain with present methods. An extensive discussion of these issues is given by Brigg et al. ${ }^{84}$

TABLE 2. Calculated vertical excitation energies (eV).

\begin{tabular}{|c|c|c|c|c|}
\hline State & $\begin{array}{l}\mathrm{HF} \\
\left(6-311 \mathrm{G}^{*}\right)\end{array}$ & $\begin{array}{l}\mathrm{HF} \\
\text { (cc-pVTZ) }\end{array}$ & $\begin{array}{l}\text { CASSCF } \\
\left(6-311 G^{*}\right)\end{array}$ & $\begin{array}{l}\text { CASSCF } \\
\text { (cc-pVTZ) }\end{array}$ \\
\hline \multicolumn{5}{|l|}{$\mathrm{X} 1 \mathrm{~A}^{\prime}$} \\
\hline a3 $\mathrm{A}^{\prime}$ & 8.045997 & 8.075928 & 6.571215 & 6.758964 \\
\hline $\mathrm{A} 1 \mathrm{~A}^{\prime}$ & 8.405169 & 8.380680 & 7.251465 & 7.387515 \\
\hline b3 $\mathrm{A}^{\prime}$ & 9.455475 & 9.441870 & 8.48952 & 9.403776 \\
\hline c3A" & 9.485410 & 9.460917 & 8.777946 & 9.558873 \\
\hline B1A" & 9.684039 & 9.635061 & 11.77105 & 9.635061 \\
\hline $\mathrm{C} 1 \mathrm{~A}^{\prime}$ & 9.697644 & 9.659550 & 11.78465 & 9.367782 \\
\hline d3A" & 9.738459 & 9.694923 & 12.90842 & 10.203750 \\
\hline D1A" & 9.945255 & 9.874509 & 12.95196 & 10.451361 \\
\hline e $3 A^{\prime}$ & 10.03233 & 9.947976 & 12.97373 & 10.560201 \\
\hline $\mathrm{E} 1 \mathrm{~A}^{\prime}$ & 10.26633 & 10.152051 & 13.20501 & 10.576527 \\
\hline
\end{tabular}


Rotational inelastic cross sections from $J=0$ to $J=0-5$ are calculated using the POLYDCS code ${ }^{85}$ with scattering, K-matrices up the first vertical excitation threshold of CPA, and orbitals constructed using cc-pVTZ orbitals. The molecular geometry of the CPA used for the calculation, shown in Table 3 , is taken from the NIST CCCBDB website. ${ }^{86}$ Dipole moment of the target, equal to $1.19 \mathrm{D}$, is obtained from the available experimental data ${ }^{87}$ and a Born correction is used for partial waves with $l$ greater than 4 for the calculation of cross sections. Low energy rotational excitation is strongly controlled by the strength of the scattering dipole. ${ }^{88}$ Thus, provided the experimental dipole is reliable, these cross sections should be accurate too.

TABLE 3. Geometry of CPA in the centre-of-mass frame.

\begin{tabular}{llll}
\hline State & $\mathrm{x}(\AA)$ & $\mathrm{y}(\AA)$ & $\mathrm{z}(\AA)$ \\
\hline $\mathrm{C}$ & -0.32 & -0.878 & -0.7512 \\
$\mathrm{C}$ & -0.32 & -0.878 & 0.7512 \\
$\mathrm{C}$ & -0.32 & 0.421 & 0.0 \\
$\mathrm{H}$ & -1.2253 & -1.1755 & -1.2726 \\
$\mathrm{H}$ & 0.6085 & -1.1458 & -1.2463 \\
$\mathrm{H}$ & -1.2253 & -1.1755 & 1.2726 \\
$\mathrm{H}$ & 0.6085 & -1.1458 & 1.2463 \\
$\mathrm{H}$ & -1.2671 & 0.9693 & 0.0 \\
$\mathrm{~N}$ & 0.908 & 1.1644 & 0.0 \\
$\mathrm{H}$ & 0.9523 & 1.768 & -0.8168 \\
$\mathrm{H}$ & 0.9523 & 1.768 & 0.8168 \\
\hline \hline
\end{tabular}

The calculation of ionisation and dissociative ionisation cross sections is performed after calculating the threshold energies (Table 2) for cation-radical fragments production and measuring their branching ratios by mass spectrometry. The calculation assumes that only one 
channel exists for the production of each set of cation-radical. Thresholds and branching ratios are summarized in Table 4.

TABLE 4. Threshold energies and branching ratios for cation-radical fragment production.

\begin{tabular}{|c|c|c|c|c|c|}
\hline \multirow{2}{*}{ Cation-radical fragments } & \multicolumn{4}{|c|}{ Branching ratio at energy $(\mathrm{eV})$} & \multirow{2}{*}{ Threshold (eV) } \\
\hline & 10 & 15 & 20 & 50 & \\
\hline $\mathrm{C}_{3} \mathrm{H}_{5} \mathrm{NH}_{2}{ }^{+}$ & 1 & 0.404 & 0.338 & 0.173 & 8.8 \\
\hline $\mathrm{C}_{3} \mathrm{H}_{3}+\mathrm{NH}_{4}^{+}$ & 0 & 0.016 & 0.043 & 0.054 & 9.75 \\
\hline $\mathrm{C}_{3} \mathrm{H}_{4}+\mathrm{NH}_{3}^{+}$ & 0 & 0.113 & 0.572 & 0.109 & 10.834 \\
\hline $\mathrm{NH}_{3}+\mathrm{C}_{3} \mathrm{H}_{4}^{+}$ & 0 & 0 & 0.129 & 0.017 & 10.834 \\
\hline $\mathrm{H}_{2}+\mathrm{C}_{3} \mathrm{H}_{3} \mathrm{NH}_{2}^{+}$ & 0 & 0.024 & 0.036 & 0.023 & 11.134 \\
\hline $\mathrm{C}_{3} \mathrm{H}_{5}+\mathrm{NH}_{2}^{+}$ & 0 & 0 & 0.098 & 0.039 & 11.918 \\
\hline $\mathrm{NH}_{2}+\mathrm{C}_{3} \mathrm{H}_{5}^{+}$ & 0 & 0.003 & 0.204 & 0.027 & 11.918 \\
\hline $\mathrm{C}_{3} \mathrm{H}_{4} \mathrm{NH}_{2}+\mathrm{H}^{+}$ & 0 & 0 & 0.055 & 0.008 & 12.226 \\
\hline $\mathrm{H}+\mathrm{C}_{3} \mathrm{H}_{4} \mathrm{NH}_{2}^{+}$ & 0.127 & 1 & 0.091 & 0.639 & 12.226 \\
\hline $\mathrm{C}_{3} \mathrm{H}_{6}+\mathrm{NH}^{+}$ & 0 & 0 & 0.053 & 0.049 & 12.395 \\
\hline $\mathrm{NH}+\mathrm{C}_{3} \mathrm{H}_{6}{ }^{+}$ & 0 & 0.007 & 0.117 & 0.023 & 12.395 \\
\hline $\mathrm{C}_{2} \mathrm{H}_{3}+\mathrm{CH}_{3} \mathrm{NH}^{+}$ & 0 & 0.207 & 0.195 & 0.319 & 13.05 \\
\hline $\mathrm{NH}_{3}+\mathrm{H}_{2}+\mathrm{C}_{3} \mathrm{H}_{2}^{+}$ & 0 & 0 & 0.005 & 0.013 & 13.168 \\
\hline $2 \mathrm{H}_{2}+\mathrm{C}_{3} \mathrm{HNH}_{2}{ }^{+}$ & 0 & 0.008 & 0.015 & 0.013 & 13.468 \\
\hline $\mathrm{CH}_{2} \mathrm{NH}+\mathrm{C}_{2} \mathrm{H}_{4}^{+}$ & 0 & 0.157 & 0.5 & 0.5 & 13.653 \\
\hline $\mathrm{NH}_{2}+\mathrm{H}_{2}+\mathrm{C}_{3} \mathrm{H}_{3}{ }^{+}$ & 0 & 0 & 0.063 & 0.053 & 14.252 \\
\hline $\mathrm{C}_{2} \mathrm{H}_{4}+\mathrm{CH}_{2} \mathrm{NH}^{+}$ & 0 & 0.037 & 0.178 & 0.168 & 14.295 \\
\hline $\mathrm{H}+\mathrm{H}_{2}+\mathrm{C}_{3} \mathrm{H}_{2} \mathrm{NH}_{2}^{+}$ & 0 & 0.022 & 0.029 & 0.088 & 14.56 \\
\hline $\mathrm{CH}_{2} \mathrm{NH}_{2}+\mathrm{C}_{2} \mathrm{H}_{3}{ }^{+}$ & 0 & 0 & 0.367 & 0.055 & 14.741 \\
\hline $\mathrm{C}_{2} \mathrm{H}_{5}+\mathrm{CNH}_{2}{ }^{+}$ & 0 & 0 & 0.5 & 0.5 & 14.827 \\
\hline $\mathrm{C}_{2} \mathrm{H}_{2}+\mathrm{CH}_{3} \mathrm{NH}_{2}{ }^{+}$ & 0 & 0.005 & 0.011 & 0.007 & 14.957 \\
\hline $\mathrm{C}_{2} \mathrm{HNH}_{2}+\mathrm{CH}_{4}^{+}$ & 0 & 0 & 0.098 & 0.039 & 15.448 \\
\hline $\mathrm{C}_{3} \mathrm{H}_{3} \mathrm{NH}_{2}+\mathrm{H}_{2}^{+}$ & 0 & 0 & 0.266 & 0.055 & 15.652 \\
\hline $3 \mathrm{H}_{2}+\mathrm{C}_{3} \mathrm{HN}^{+}$ & 0 & 0 & 0.015 & 0.014 & 16.539 \\
\hline $\mathrm{NH}_{2}+2 \mathrm{H}_{2}+\mathrm{C}_{3} \mathrm{H}^{+}$ & 0 & 0 & 0.002 & 0.007 & 16.586 \\
\hline $\mathrm{CH}+\mathrm{C}_{2} \mathrm{H}_{4} \mathrm{NH}_{2}{ }^{+}$ & 0 & 0 & 0.021 & 0.004 & 16.727 \\
\hline $\mathrm{H}+2 \mathrm{H}_{2}+\mathrm{C}_{3} \mathrm{HNH}^{+}$ & 0 & 0 & 0.015 & 0.025 & 17.371 \\
\hline
\end{tabular}




\begin{tabular}{lllllc}
$\mathrm{CH}_{2} \mathrm{NH}+\mathrm{H}+\mathrm{H}_{2}+\mathrm{C}_{2} \mathrm{H}^{+}$ & 0 & 0 & 0.015 & 0.005 & 17.766 \\
$\mathrm{C}_{3} \mathrm{H}_{2} \mathrm{NH}_{3}+\mathrm{CH}_{2}{ }^{+}$ & 0 & 0 & 0.005 & 0.013 & 17.95 \\
$\mathrm{CH}_{2}+\mathrm{C}_{2} \mathrm{H}_{3} \mathrm{NH}_{2}{ }^{+}$ & 0 & 0 & 0.047 & 0.003 & 17.95 \\
$\mathrm{C}_{2} \mathrm{H}_{4}+\mathrm{H}_{2}+\mathrm{CNH}^{+}$ & 0 & 0 & 0.367 & 0.055 & 18.632 \\
$\mathrm{CH}_{2} \mathrm{NH}+\mathrm{H}_{2}+\mathrm{C}_{2} \mathrm{H}_{2}^{+}$ & 0 & 0 & 0.862 & 0.026 & 19.243 \\
$\mathrm{C}_{2} \mathrm{H}_{5}+\mathrm{H}_{2}+\mathrm{CN}^{+}$ & 0 & 0 & 0 & 0.026 & 21.277 \\
\hline \hline
\end{tabular}

The calculated dissociative ionization cross sections are shown in Fig. 2(a) and (b). The inelastic electron-CPA cross sections leaving CPA in specific excited states and the rotational excitation cross section up to $\mathrm{J}=0-5$ are shown in Fig. 2(c) and (d), respectively.
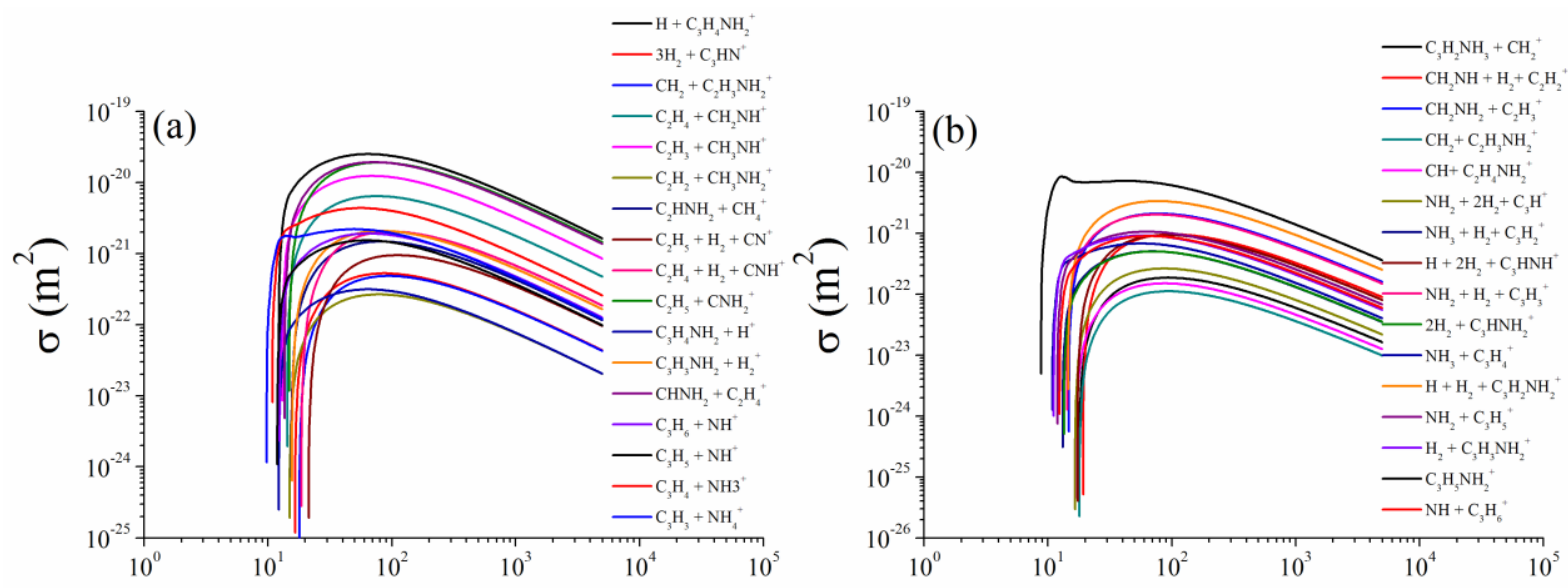

Energy (eV)
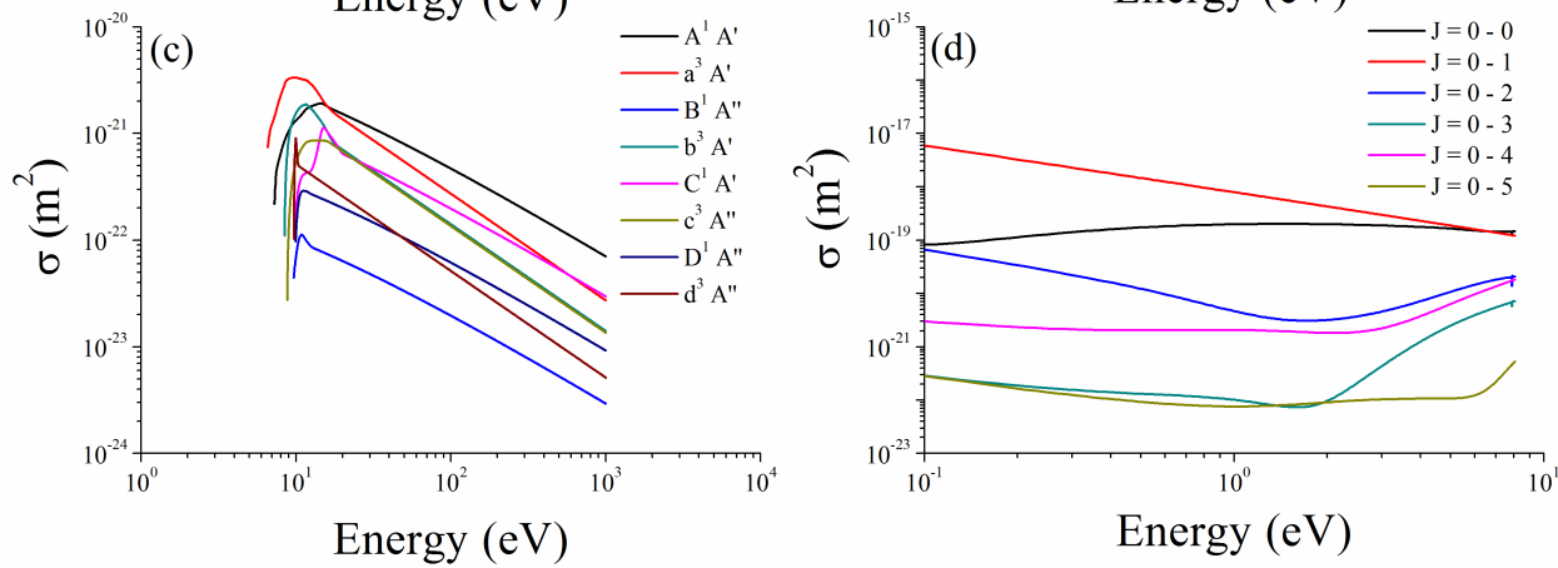

FIG. 2. Calculated cross sections of ( $a, b)$ dissociative ionization, (c) electronic excitation and (d) rotational excitation. 


\section{B. PIC-MC simulations}

Particle-In-Cell simulations combined with Monte Carlo Collisions scheme (PIC-MC) are performed by using the PIC-MC / DSMC software package developed at Fraunhofer IST. ${ }^{89-}$

${ }^{92}$ The open-source tool $\mathrm{GMSH}^{93}$ is used for the design of the reactor, as shown in Fig. 1(b), and also for post processing. Before starting PIC-MC simulations, the magnetic field generated by the permanent magnets is computed by the Boundary Element Method (BEM),${ }^{94}$ which is implemented in the same software as separate module. All magnetic parts - i.e. yoke and magnets - are represented by a separate mesh; on its boundaries, a Laplace equation for the scalar magnetic potential is solved. From this solution, the magnetic field vector is obtained for each grid position in the region of interest (i.e., where the plasma simulation takes place). The magnetic material parameter are found in Table 5. For the yoke a high relative magnetic susceptibility of $\mu_{\mathrm{Y}}=5000$ yields an effective shortcut of the magnetic field. For $\mu_{\mathrm{Y}}>100$ the magnetic field solution is insensitive on its exact value. In the subsequent PIC-MC simulation runs, the BEM computed magnetic field is considered constant, namely, convection currents occurring in the plasma are assumed to cause negligible magnetic field contributions.

In order to keep the overall computational effort feasible, the PIC-MC simulations do not include a comprehensive plasma chemical model. Instead, only the electron impact cross sections with the CPA molecules and the six most important radical species resulting from dissociative ionization are taken into account. The first run assumes a total power of $10 \mathrm{~W}$ and uses a 3D simulation grid with $1 \mathrm{~mm}$ cell spacing. A physical time interval of three pulses (i.e., $210 \mu \mathrm{s})$ is computed, and only electrons, the CPA molecule and its ion are considered. The main purpose of the first simulation run is to identify the most frequent radical generation paths by dissociative ionization as well as the mean ion energy at different positions of the drum electrode. The second PIC-MC run is subsequently performed at a lower power of $1 \mathrm{~W}$, which allows to use a larger spacing of the simulation grid of $1.5 \mathrm{~mm}$ and to increase the physical 
time interval to $1190 \mu$ s (17 pulses). Besides electrons and CPA molecules, the second run includes six more radicals, which either have the highest production rate, and/or which are especially of relevance with respect to surface functionalization. In the second run, secondary reactions between the reaction products (ions, radicals) are considered negligible and are not included in the model. However, momentum transfer cross sections between the generated species and CPA neutral molecules are included according to the Variable Soft Sphere (VSS) $\operatorname{model}^{53,95}$

To investigate the power scaling influence on numerical results, two similar simulations at 1 and $10 \mathrm{~W}$ were compared during the first three electric periods $(210 \mu \mathrm{s})$, to observe the power increase effect on plasma species densities and radical absorption on the reactor walls (results not shown). Increasing the power from 1 to $10 \mathrm{~W}$ leads to higher average plasma density and to a reduced sheath thickness at the walls, but the spatial distributions of the generated species are nevertheless similar. Moreover, the averaged fluxes of radicals absorbed on the reactor walls are seen to scale linearly with power, namely the absorption fluxes at $1 \mathrm{~W}$ are almost superimposable with the adsoption fluxes at $10 \mathrm{~W}$ divided by 10 . Consequently, we deduced that the general discharge behavior is not significantly modified by the power increase, and that $1 \mathrm{~W}$ simulations could be trustingly used to investigate the discharge properties at higher power.

TABLE 5. Physical and numerical parameters considered in the PIC-MC models.

\begin{tabular}{lll}
\hline \hline Parameter & $1^{\text {st }}$ run & $2^{\text {nd }}$ run \\
\hline Model dimension & $90 \times 90 \times 96 \mathrm{~mm}^{3}$ & $90 \times 90 \times 96 \mathrm{~mm}^{3}$ \\
Cell spacing & $1 \mathrm{~mm}$ & $1.5 \mathrm{~mm}$ \\
Magnetic remanence & $1.22 \mathrm{~T}$ & $1.22 \mathrm{~T}$ \\
Magnetic susceptibility & 1.05 & 1.05 \\
\hline \hline
\end{tabular}




\begin{tabular}{lll}
\hline \hline Yoke susceptibility & 5000 & 5000 \\
$\begin{array}{l}\text { Species (sticking } \\
\text { coefficient })^{17}\end{array}$ & $\mathrm{C}_{3} \mathrm{H}_{7} \mathrm{~N}, \mathrm{C}_{3} \mathrm{H}_{7} \mathrm{~N}^{+}, \mathrm{e}^{-}$ & $\begin{array}{l}\mathrm{C}_{3} \mathrm{H}_{7} \mathrm{~N}(0), \mathrm{C}_{3} \mathrm{H}_{7} \mathrm{~N}^{+}(1), \mathrm{e}^{-}(1), \\
\mathrm{CH}_{2} \mathrm{NH}(0.35), \mathrm{C}_{2} \mathrm{H}_{5}(0.001), \\
\end{array}$ \\
$\begin{array}{l}\mathrm{C}_{2} \mathrm{H}_{3}(0.3), \mathrm{H}(0.01), \mathrm{NH}_{2}(0.6), \\
\mathrm{NH}(0.11)\end{array}$ \\
$\begin{array}{l}\text { Time step width } \\
\begin{array}{l}\text { Physical simulation } \\
\text { time }\end{array}\end{array}$ \\
$\begin{array}{l}\text { Number of CPU cores } \\
\text { Computation time }\end{array}$ & $210 \times 10^{-12} \mathrm{~s}$ & $1190 \times 10^{-11} \mathrm{~s}$ \\
\hline \hline
\end{tabular}

The simulations are performed for studying the species generation on a qualitative basis. The present work does not aim to simulate the PPF growth. Consequently, most of surface processes, such as chemical reactions, progressive modification of surface conditions, surface diffusion, sputtering, implantation, heat transfer, etc., are neglected. However, to obtain information about the deposition rate distribution, a sticking coeficient was set for each species (Table 5) and their absorption rates were monitored. Additionally, secondary electron emission is also included in the model.

\section{Results}

\section{A. Experimental characterization of plasma polymer films}

The deposition rates are measured by profilometry and SEM. Both techniques give approximately the same values, namely $27.2 \pm 5.8 \mathrm{~nm} \mathrm{~min}^{-1}$ at position $\mathrm{A}$ and $10.6 \pm 0.6 \mathrm{~nm}$ $\min ^{-1}$ at position B. Thus, the deposition rates are about 2.57 times higher in the high magnetic field region. Fig. 3 shows SEM cross sectional images of the two samples. At position B, the PPF is smooth and adheres well to the substrate. However, at position A, the PPF exibits local delaminations. 

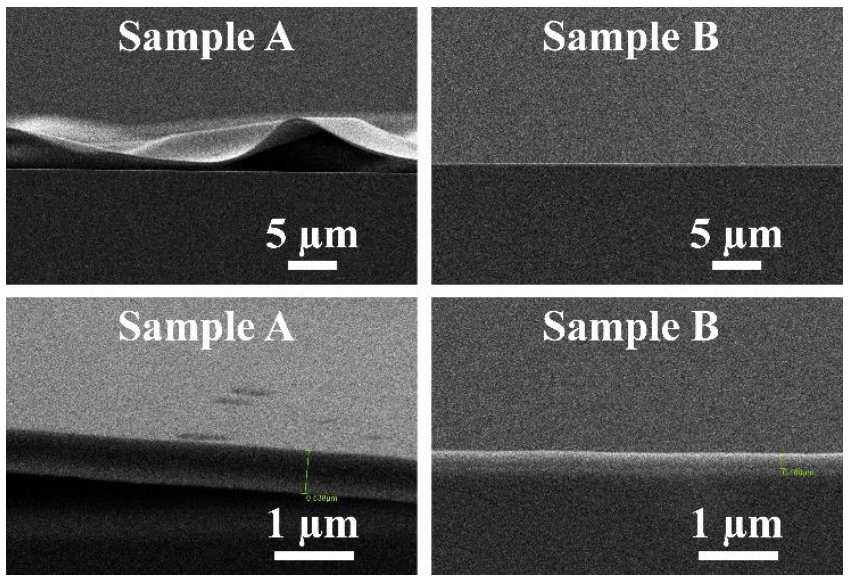

FIG. 3. SEM cross sectional views of samples A and B.

The delamination of PPFs is described under different names in the literature, such as curling, ${ }^{12}$ buckling, ${ }^{96}$ or blistering. ${ }^{97}$ This phenomenon is attributed to excessive stresses arising in the coating under certain circumstances. First, the continuous adsorption of various building blocks combined with constant ion bombardment can generate a wedging effect leading to growth-induced internal stresses that increase with the layer thickness. ${ }^{12,98}$ Second, the delamination can also be explained by a thermal expansion mismatch between the polymer layer and the substrate. Indeed, the thermal expansion coefficient of silicon $\left(2-4 \times 10^{-6} \mathrm{~K}^{-1}\right)$ is much lower than the one of polymers (some tens to some hundreds of $10^{-6} \mathrm{~K}^{-1}$ ), ${ }^{97}$ which can lead to post-treatment compressive stresses in the coating if the substrate undergoes significant heating during the deposition. ${ }^{96}$ Third, post-deposition environmental attacks such as oxidation or moisture absorption can also induce stresses in the PPF, mainly in the case of porous coatings. ${ }^{97,98}$ The delamination occurs when the stresses in the coating exceed the adhesive forces at the interface with the substrate. Based on these elements, the delamination at position A could be explained by a higher substrate heating induced by a stronger ion bombardment compared with position B. The heating of a surface subjected to ion bombardment is a largely known phenomenon in physical vapor deposition processes. ${ }^{99,100}$ It results from the partial conversion of impinging ions kinetic energy into heat. This phenomenon is greatly exacerbated 
in low pressure conditions due to the greater ion mean free path and reduced surface cooling by heat transfer to the surrounding gas. This explains why the cathodes are generally watercooled in magnetron discharges. As no cooling system is present in our low pressure discharge, the higher ion bombardment at position A could generate higher internal stresses and a higher substrate heating resulting in a greater thermal expansion mismatch between the silicon substrate and the PPF.

The elemental composition of samples A and B measured by XPS is shown in Table 6, together with the corresponding $[\mathrm{N}] /[\mathrm{C}]$ ratios. The oxygen detected is attributed to PPFs postplasma oxidation. ${ }^{3}$ The $[\mathrm{N}] /[\mathrm{C}]$ ratio ranges between 0.147 (sample A) and 0.161 (sample $\mathrm{B}$ ). This ratio is lower than the one measured by XPS in other studies dealing with plasma polymerization of CPA, which can reach values between 0.2 and $0.26 .^{24,25,32}$ This difference is likely related to the difference in operating conditions and reactor design. Indeed, in the latter studies, the plasma is ignited by an RF power supply $(13.56 \mathrm{MHz})$ and the substrate is kept at floating potential, while in our configuration, the excitation frequency is much lower $(\sim 14.3$ $\mathrm{kHz}$ ) and the substrate is directly placed onto the high voltage electrode. Therefore, in our case, ions have more time to be accelerated by the applied electric field before the polarity reverses, and the substrate potential (between -400 and $-500 \mathrm{~V}$ ) is much higher (in absolute value) than the one reached in the case of floating surface (about $-20 \mathrm{~V}$ for low pressure discharge). This leads to a much more intense surface ion bombardment during the deposition in our configuration. The link between lower nitrogen incorporation and stronger ion bombardment is also supported by the lower $[\mathrm{N}] /[\mathrm{C}]$ ratio at position A (high magnetic field region) than at position B (low magnetic field region), as discussed later.

TABLE 6. Elemental concentrations of samples A and B measured by XPS.

\begin{tabular}{ccc}
\hline \hline Sample & Elemental concentrations (at. \%) $\quad[\mathrm{N}] /[\mathrm{C}]$ \\
\hline \hline
\end{tabular}




\begin{tabular}{ccccc}
\hline \hline & C1s & N1s & O1s & \\
\hline Sample A & $83 \pm 0.6$ & $12.2 \pm 0.3$ & $4.8 \pm 0.7$ & $0.147 \pm 0.005$ \\
Sample B & $82.5 \pm 0.6$ & $13.3 \pm 0.2$ & $4.2 \pm 0.7$ & $0.161 \pm 0.005$ \\
\hline \hline
\end{tabular}

To investigate with greater details the thin film chemistries at both positions, the XPS high resolution spectra of $\mathrm{C} 1 \mathrm{~s}$ and N1s peaks are fitted with three components corresponding to different bond configurations, as shown in Fig. 4. Assignments of the different components are done based on available literature ${ }^{101}$ and the concentrations of the different contributions are gathered in Table 7.

TABLE 7. Concentrations and characteristics of the different components used for fitting XPS high resolution spectra of $\mathrm{C} 1 \mathrm{~s}$ and $\mathrm{N} 1 \mathrm{~s}$ peak at positions $\mathrm{A}$ and $\mathrm{B}$.

\begin{tabular}{|c|c|c|c|c|c|c|c|}
\hline \multirow{3}{*}{$\begin{array}{c}\text { Element } \\
\text { Position }(\mathrm{eV})\end{array}$} & \multicolumn{7}{|c|}{ Concentration $(\%)$} \\
\hline & \multicolumn{4}{|c|}{$\mathrm{C} 1 \mathrm{~s}$} & \multicolumn{3}{|c|}{ N1s } \\
\hline & 285 & 286.5 & 288 & 289.5 & 398 & 399.2 & 400.5 \\
\hline Component & $\begin{array}{l}\mathrm{C}-\mathrm{C} \\
\mathrm{C}-\mathrm{H}\end{array}$ & $\begin{array}{l}\mathrm{C}-\mathrm{N} \\
\mathrm{C}=\mathrm{N} \\
\mathrm{C} \equiv \mathrm{N} \\
\mathrm{C}-\mathrm{O}\end{array}$ & $\begin{array}{c}\mathrm{C}=\mathrm{O} \\
\mathrm{N}-\mathrm{C}=\mathrm{O}\end{array}$ & $\mathrm{COOH}$ & $\begin{array}{c}\mathrm{N}=\mathrm{C} \\
\mathrm{N}=\mathrm{C}=\mathrm{N}\end{array}$ & $\mathrm{NH}_{\mathrm{x}}$ & $\begin{array}{c}\mathrm{N} \equiv \mathrm{C} \\
\mathrm{N}-\mathrm{C}=\mathrm{O}\end{array}$ \\
\hline Sample A & 74.1 & 19.6 & 4.3 & 2.0 & 1.2 & 73.1 & 25.7 \\
\hline Sample B & 72.6 & 21.8 & 4.2 & 1.4 & 2.3 & 75.4 & 22.3 \\
\hline
\end{tabular}



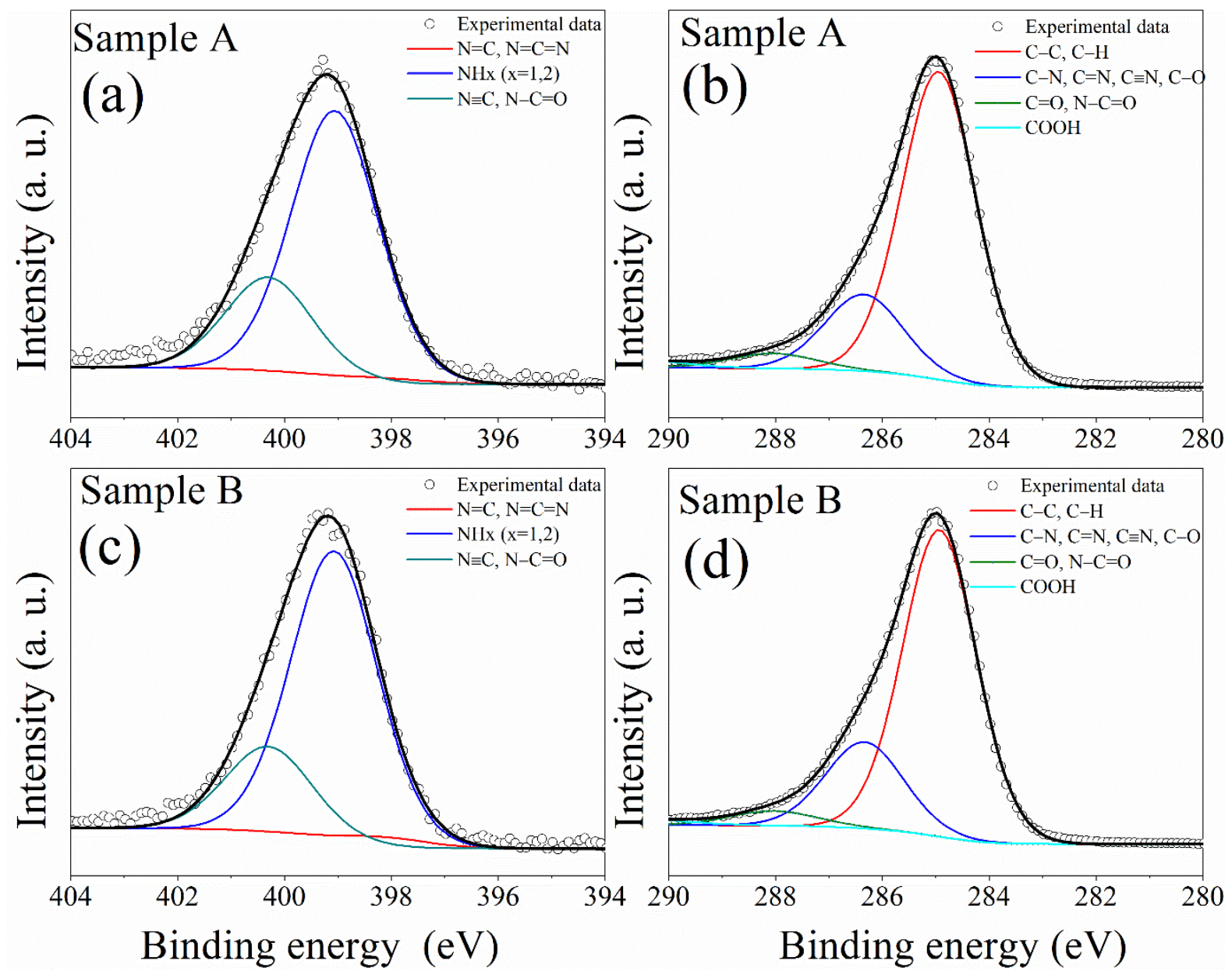

FIG. 4. XPS fitting of high resolution spectra of (a) N1s peak of sample A, (b) C1s peak of sample A, (c) N1s peak of sample B, (d) C1s peak of sample B.

Both samples exhibit quite close chemistries. Nevertheless, sample B shows a slightly higher content of primary/secondary amine $\left(\mathrm{NH}_{\mathrm{x}}\right)$ groups and slightly lower content of nitrile $(\mathrm{C} \equiv \mathrm{N})$ and amide $(\mathrm{N}-\mathrm{C}=\mathrm{O})$ groups compared to sample A. Also, sample A contains more $\mathrm{C}-$ $\mathrm{C} / \mathrm{C}-\mathrm{H}$ bonds and less $\mathrm{CN}$ bonds than sample $\mathrm{B}$, which further confirms the lower nitrogen incorporation at position $\mathrm{A}$.

To obtain further information about the thin film chemistry at positions $\mathrm{A}$ and $\mathrm{B}$, the samples have been analyzed by TOF-SIMS. The resulting scores and loadings plots obtained after PCA analysis of the measured spectra are depicted in Fig. 5. The first two PCs displayed explain $99 \%$ of the overall variance, with $96 \%$ for $\mathrm{PC}_{1}$ and $3 \%$ for $\mathrm{PC}_{2}$. While no clear 
distinction can be done between both samples along $\mathrm{PC}_{2}$ axis, a marked difference is observed along $\mathrm{PC}_{1}$ axis. Indeed, the scores related to sample $\mathrm{A}$ are negative while the scores related to sample B are positive.
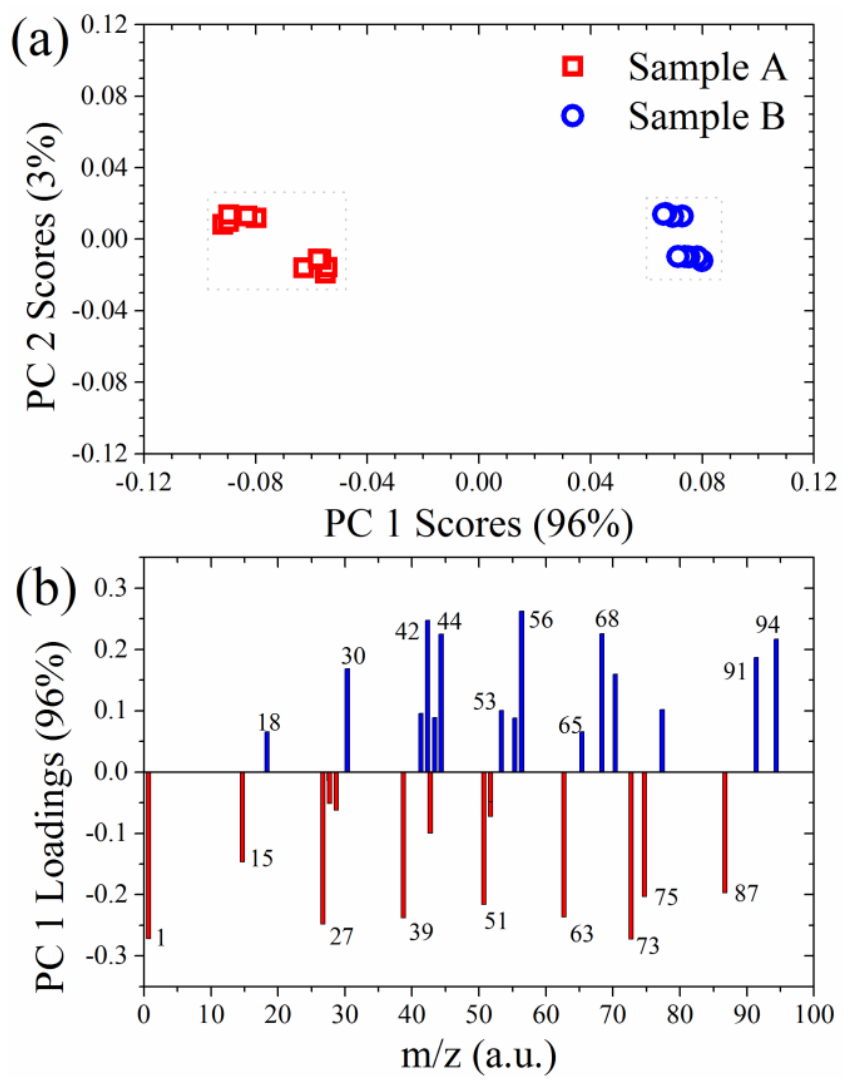

FIG. 5. (a) Scores plot and (b) loadings plot obtained from PCA analysis of TOF-SIMS spectra of samples A and B.

To determine the differences in terms of chemical composition between samples A and B, the scores plot has to be compared with the associated loadings plot depicted in Fig. 5(b). The loadings plot gives the contribution of the different TOF-SIMS peaks to the different PCs, and enables to identify the fragments responsible for the differences observed between the samples. From Fig. 5(b), we deduce that the fragments having m/z equal to $1\left(\mathrm{H}^{+}\right), 15\left(\mathrm{CH}_{3}{ }^{+}\right)$, $27\left(\mathrm{C}_{2} \mathrm{H}_{3}{ }^{+}\right), 29\left(\mathrm{C}_{2} \mathrm{H}_{5}^{+}\right), 39\left(\mathrm{C}_{3} \mathrm{H}_{3}^{+}\right), 43\left(\mathrm{C}_{2} \mathrm{H}_{5} \mathrm{~N}^{+}\right), 51\left(\mathrm{C}_{4} \mathrm{H}_{3}^{+}\right), 52\left(\mathrm{C}_{3} \mathrm{H}_{2} \mathrm{~N}^{+}\right), 63\left(\mathrm{C}_{5} \mathrm{H}_{3}{ }^{+}\right), 73$ $\left(\mathrm{C}_{3} \mathrm{H}_{7} \mathrm{NO}^{+}\right), 75\left(\mathrm{C}_{6} \mathrm{H}_{3}{ }^{+}\right)$and $87\left(\mathrm{C}_{7} \mathrm{H}_{3}{ }^{+}\right)$are more representative of sample A because they have 
negative loadings. Similarly, the fragments at $\mathrm{m} / \mathrm{z}$ equal to $18\left(\mathrm{NH}_{4}+\right), 30\left(\mathrm{CH}_{4} \mathrm{~N}^{+}\right), 41\left(\mathrm{C}_{3} \mathrm{H}_{5}{ }^{+}\right)$, $42\left(\mathrm{C}_{2} \mathrm{H}_{4} \mathrm{~N}^{+}\right), 43\left(\mathrm{C}_{3} \mathrm{H}_{7}^{+}\right), 53\left(\mathrm{C}_{4} \mathrm{H}_{5}^{+}\right), 55\left(\mathrm{C}_{4} \mathrm{H}_{7}{ }^{+}\right), 56\left(\mathrm{C}_{3} \mathrm{H}_{6} \mathrm{~N}^{+}\right), 65\left(\mathrm{C}_{5} \mathrm{H}_{5}^{+}\right), 68\left(\mathrm{C}_{4} \mathrm{H}_{6} \mathrm{~N}^{+}\right), 70$ $\left(\mathrm{C}_{4} \mathrm{H}_{8} \mathrm{~N}^{+}\right), 77\left(\mathrm{C}_{6} \mathrm{H}_{5}^{+}\right), 91\left(\mathrm{C}_{7} \mathrm{H}_{7}+\right)$ and $94\left(\mathrm{C}_{6} \mathrm{H}_{8} \mathrm{~N}^{+}\right)$, which have positive loadings, better characterize sample B. From these data, it emerges that most of nitrogen-containing fragments have positive loadings and are therefore more present in sample B. Consequently, TOF-SIMS results corroborates XPS data concerning the higher nitrogen incorporation in the PPF deposited at position B (low magnetic field region).

Information about the degree of cross-linking of the PPFs can also be extracted from PCA analysis by calculating an averaged $\mathrm{C}_{\mathrm{x}} \mathrm{H}_{\mathrm{y}}{ }^{+}$fragment from the most intense peaks of the loadings plot. Nitrogen-containing fragments are also considered for the calculation, by replacing each $\mathrm{N}$ atom by a $\mathrm{CH}$ group. ${ }^{5}$ The resulting $[\mathrm{C}] /[\mathrm{H}]$ ratio can be related to the unsaturated carbon content and to the degree of cross-linking. In the present case, the calculation gives a $[\mathrm{C}] /[\mathrm{H}]$ ratio equal to 1.02 at position $\mathrm{A}$ and 0.67 at position $\mathrm{B}$, which indicates a higher degree of cross-linking at position A (high magnetic field region). To summarize, TOF-SIMS analyses indicate that the nitrogen incorporation and the degree of cross-linking follow opposite trends depending on the magnetic field strength. The PPF deposition in the low magnetic field results in a higher nitrogen incorporation but a lower degree of cross-linking than in the high magnetic field region.

The higher degree of unsaturation at position A is also supported by IBA measurements. Elemental depth profiles determined with this technique are shown in Fig. 6. The corresponding elemental concentrations are gathered in Table 8. The results show that elemental concentrations are constant throughout the PPFs depth. Moreover, the $[\mathrm{C}] /[\mathrm{H}]$ ratio decreases by about $29 \%$ between position A (2.05) and B (1.46), which is in good agreement with TOFSIMS/PCA results, which give a drop in $[\mathrm{C}] /[\mathrm{H}]$ ratio of about $34 \%$ between position $\mathrm{A}(1.02)$ and B (0.67). The differences observed between the two techniques in the calculation of the 
$[\mathrm{C}] /[\mathrm{H}]$ ratio are likely due to the approximations made during PCA treatment. Indeed, in the last case, only the most influential TOF-SIMS peaks are considered (determined by statistical analysis), and $\mathrm{N}$ atoms are replaced by $\mathrm{CH}$ groups for the calculation. Despite these approximations, both techniques reveals close variations in $[\mathrm{C}] /[\mathrm{H}]$ ratios between the two positions investigated, and confirm the higher hydrogen deficiency at position A.

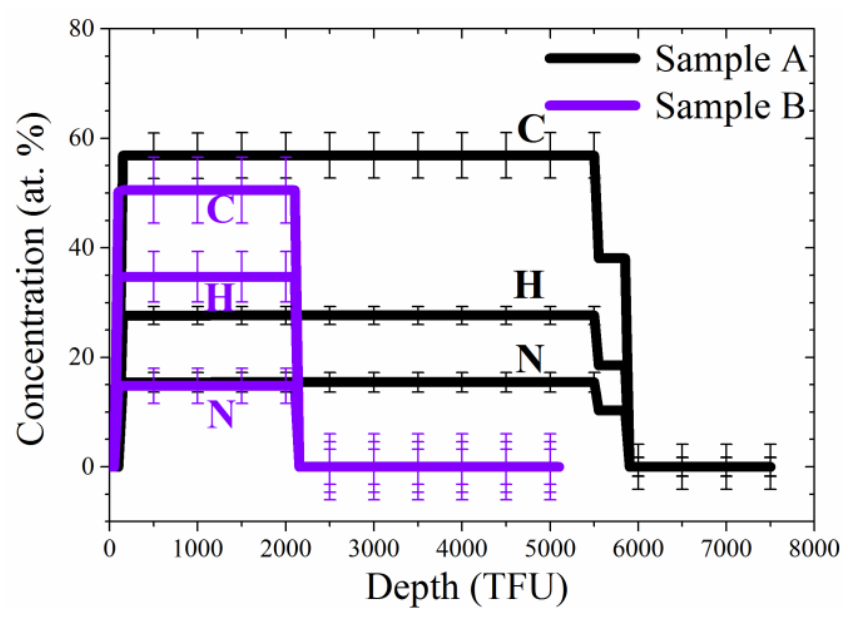

FIG. 6. Elemental depth profiles of samples A and B measured by IBA.

TABLE 8. Elemental concentrations of samples A and B measured by IBA.

\begin{tabular}{|c|c|c|c|c|c|}
\hline \multirow{2}{*}{ Sample } & \multicolumn{3}{|c|}{ Elemental concentrations (at. \%) } & \multirow{2}{*}[\mathrm{C}]{$/[\mathrm{H}]$} & \multirow{2}{*}[\mathrm{N}]{$/[\mathrm{C}]$} \\
\hline & $\mathrm{C}$ & $\mathrm{N}$ & $\mathrm{H}$ & & \\
\hline Sample A & $56.9 \pm 4.1$ & $15.4 \pm 1.8$ & $27.7 \pm 1.6$ & 2.05 & 0.27 \\
\hline Sample B & $50.5 \pm 6$ & $14.8 \pm 3.3$ & $34.7 \pm 4.6$ & 1.46 & 0.29 \\
\hline
\end{tabular}

Moreover, as in the case of XPS analyses, the $[\mathrm{N}] /[\mathrm{C}]$ ratio measured by IBA reveals a slightly higher nitrogen incorporation at position B than at position A, with good agreement between the two techniques (+9\% for XPS, $+7 \%$ for IBA). Nevertheless, the $[\mathrm{N}] /[\mathrm{C}]$ ratios measured by IBA are substantially higher than the ones measured by XPS (e.g., 0.27 instead of 0.147 at position A). This difference is likely related to the different depths of analysis 
between the two techniques. Indeed, XPS only analyzes the first 5-10 $\mathrm{nm}$ of the surface and is more sensitive to carbon contamination, while IBA scans the whole samples depth.

As the IBA technique indicates the number of atoms per square centimeter for each element present in the PPF, it is possible to deduce the mass of each element per square centimeter, and ultimately, by dividing the result by the PPF thickness, to obtain the "partial density" (in $\mathrm{g} \mathrm{cm}^{-3}$ ) for each thin film constituent. The sum of all "partial densities" allows determining the PPF density at the different positions investigated. By doing so, we measure PPF densities of $2.0 \pm 0.4 \mathrm{~g} \mathrm{~cm}^{-3}$ at position $\mathrm{A}$ and $1.7 \pm 0.3 \mathrm{~g} \mathrm{~cm}^{-3}$ at position $\mathrm{B}$. These values are markedly higher than the ones measured in the literature for PPFs synthesized from CPA or its allylamine isomer in similar power conditions, which range between 1.1 and $1.5 \mathrm{~g} \mathrm{~cm}^{-}$ ${ }^{3} \cdot{ }^{26,102}$ Once again, this difference could be explained by our different reactor geometry and excitation mode, that would lead to a more intense ion bombardment during the PPF growth. Such a bombardment would lead, in turn, to stronger PPF sputtering and hydrogen abstraction, generating more dangling bonds on the polymer surface, resulting in higher degree of crosslinking and PPF density after thin film restructuring.

\section{B. Plasma simulations}

The first run of plasma simulation is performed with $\mathrm{C}_{3} \mathrm{H}_{7} \mathrm{~N}, \mathrm{C}_{3} \mathrm{H}_{7} \mathrm{~N}^{+}$and $\mathrm{e}^{-}$as reactive species, by implementing the calculated cross sections. Besides tracking the production rates of radicals, $\mathrm{C}_{3} \mathrm{H}_{7} \mathrm{~N}^{+}$ion properties are investigated. Fig. 7 depicts the spatial distribution of the electric potential, electron and ion densities, and ion energy averaged over a negativelypolarized drum period of $10 \mu$ s (between 141 and $150 \mu$ s, when ions are directed to the drum), in order to study the ions behavior at positions A and B during PPF deposition. 

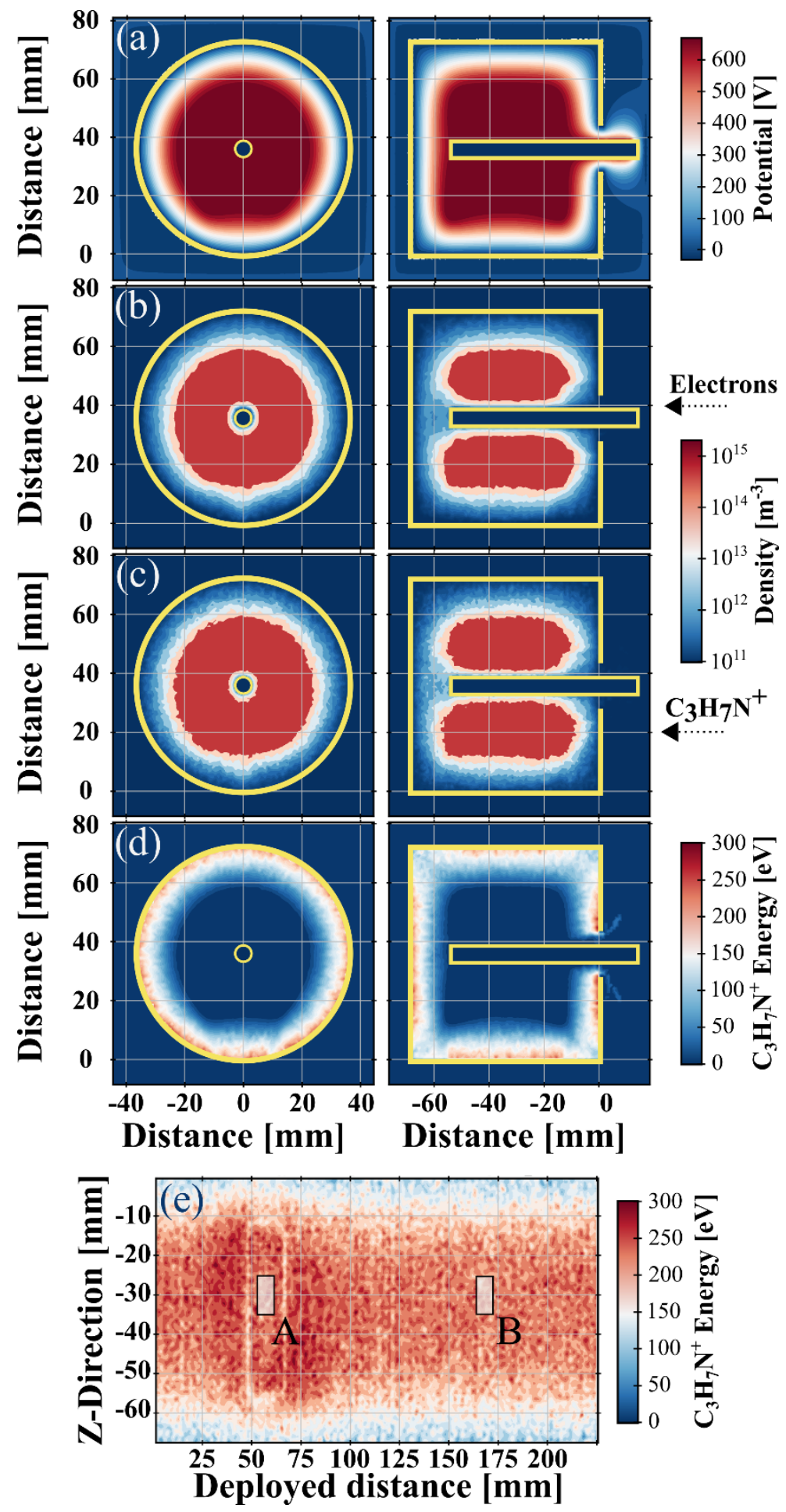

FIG. 7. Face view and side view of the spatial distribution of (a) electric potential, (b) electron density, (c) $\mathrm{C}_{3} \mathrm{H}_{7} \mathrm{~N}^{+}$density and (d) $\mathrm{C}_{3} \mathrm{H}_{7} \mathrm{~N}^{+}$energy averaged over $10 \mu$ s (between 141 and 150 $\mu$ s). (e) Corresponding 2D energy mapping of $\mathrm{C}_{3} \mathrm{H}_{7} \mathrm{~N}^{+}$ion reaching the unrolled drum surface. The 0 position on the $\mathrm{x}$-axis relates to the leftmost position of the drum in the xy plane. The 
two positions $\mathrm{A}$ and $\mathrm{B}$ where $1 \times 1 \mathrm{~cm}^{2} \mathrm{Si}$ wafers have been placed for experimental investigations are indicated by small rectangles.

From Fig. 7(d) and (e), the average ion energy near magnets (position A) is about $35 \%$ higher than in the opposite position (position B). The reason is likely related the the magnetic field lines, which are responsible for a slight depletion in charged species densities near position A (Fig. 7(b) and (c)). Thus, ions reaching this position are more likely originating from central positions of the reactor. Therefore, ions reaching the wall at position A have - in average - seen a greater potential difference compared to ions hitting other wall regions.

According to volume and time averaged collision statistics determined during the first simulation run, the radicals mostly generated in the plasma (and corresponding threshold energies) are $\mathrm{H}(12.226 \mathrm{eV}), \mathrm{CH}_{2} \mathrm{NH}(13.653 \mathrm{eV}), \mathrm{C}_{2} \mathrm{H}_{5}(14.827 \mathrm{eV})$ and $\mathrm{C}_{2} \mathrm{H}_{3}(13.050 \mathrm{eV})$. These radicals have thus been considered in the second simulation run, to study their spatial generation and diffusion inside the plasma reactor. Additionally, $\mathrm{NH}_{2}$ and $\mathrm{NH}$ radicals have been included in the second run, because they are expected to contribute to surface functionalization. For each of the radicals, a sticking coefficient taken from the work of Mao and Bogaerts ${ }^{17}$ is attributed (Table 5), in order to track their absorption on the reactor walls, notably at positions $A$ and $B$. The sticking coefficient of $\mathrm{C}_{3} \mathrm{H}_{7} \mathrm{~N}^{+}$ions is assumed to be unity, ${ }^{17,103}$ while a sticking coefficient of 0 is used for CPA molecules, because they are considered to be reflected at the walls. ${ }^{17}$

The spatial density distributions of the different radicals investigated, of electrons and $\mathrm{C}_{3} \mathrm{H}_{7} \mathrm{~N}^{+}$ions, are depicted in Fig. 8. These distributions are averaged over the two last periods of the plasma simulation, namely from the $15^{\text {th }}$ to the $17^{\text {th }}$ period $(1050-1190 \mu \mathrm{s})$. For all radicals (Fig. 8(a)-(f)), the generation mainly takes place around the gas shower and near magnets edges, as a result of the higher electron densities (and thus collision rates) in these 
areas (Fig. 8(g)). Similarly, areas of highest ion density coincide with those of highest electron densities.
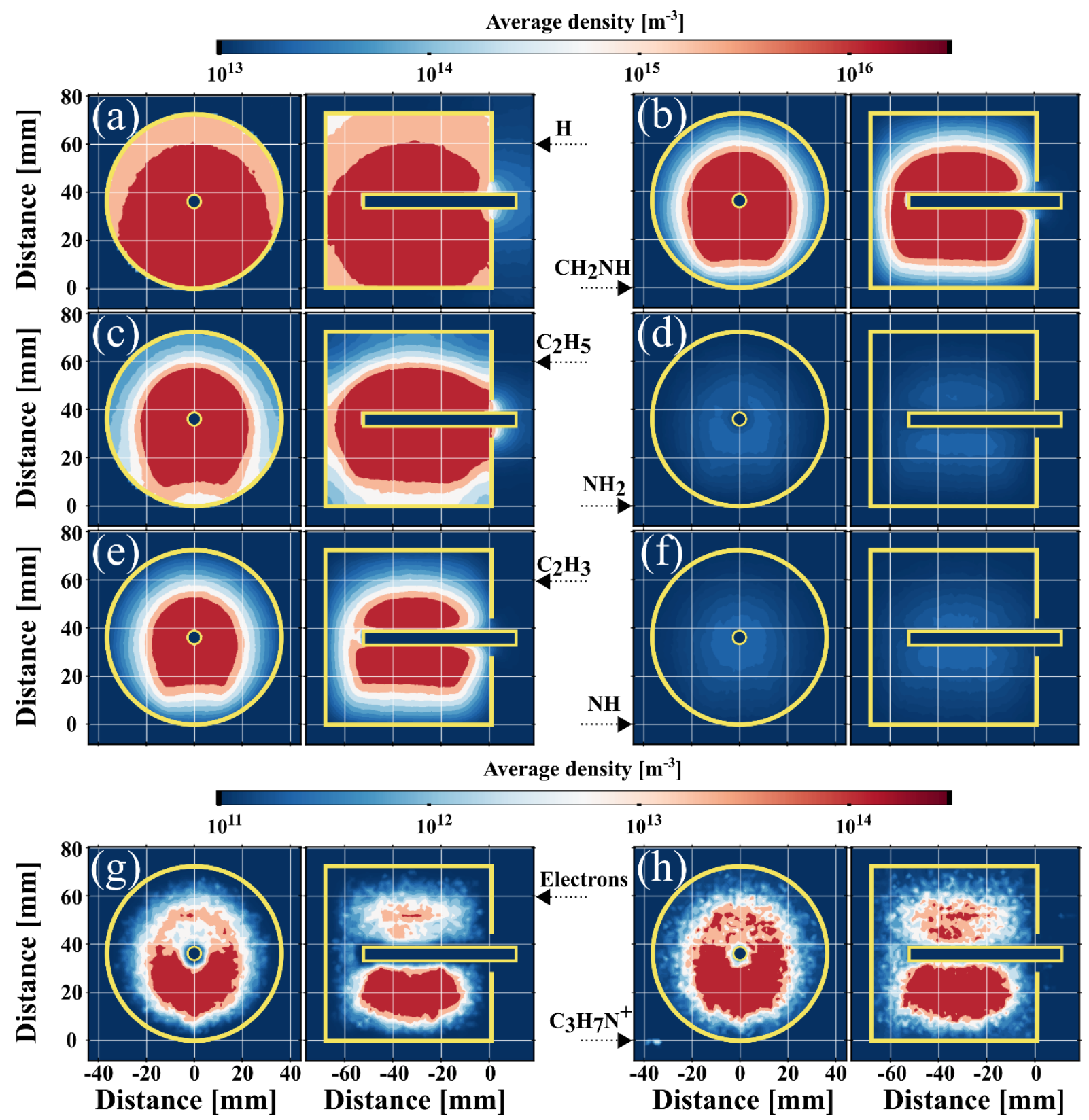

Fig. 8. Face view (left) and side view (right) of the spatial density distribution of (a) H, (b)

$\mathrm{CH}_{2} \mathrm{NH}$, (c) $\mathrm{C}_{2} \mathrm{H}_{5}$, (d) $\mathrm{NH}_{2}$, (e) $\mathrm{C}_{2} \mathrm{H}_{3}$, and (f) $\mathrm{NH}$ radicals, of (g) electrons and (h) $\mathrm{C}_{3} \mathrm{H}_{7} \mathrm{~N}^{+}$ions.

The displayed data are averaged over two periods, from the $15^{\text {th }}$ to the $17^{\text {th }}$ period $(1050-1190$ $\mu \mathrm{s})$. Let us note that color gradient bars are different for radicals and charged species due to the much smaller densities of the latters. 
To compare in a more quantitative way the densities of the different species, two $1 \mathrm{~cm}$ in diameter virtual spherical volumes, named $A^{\prime}$ and $B^{\prime}$, located in the middle of the drum along z-axis and halfway between the gas shower and positions A and B, respectively, have been defined (Fig. 1(b)). The average densities of the different species calculated in these two volumes during the period 1050-1190 $\mu$ s are gathered in Table 9. Average densities are systematically higher in volume $A^{\prime}$ than in volume $B^{\prime}$, as a result of the electron magnetic confinement near magnets, which leads to higher collision rates. Nevertheless, as neutral radical species are not directly affected by electromagnetic fields and can diffuse more freely in the reactor, the average densities of radicals are only 1.2 to 1.4 times higher in volume $A$ ' than in $B^{\prime}$, while they are 2.3 to 2.5 times higher in the case of charged species.

TABLE 9. Average densities of the different species calculated over two periods, from 1050 to $1190 \mu \mathrm{s}$, in the two volumes $A$ ' and $B$ ' defined in Fig. 1(b).

\begin{tabular}{ccccccccc}
\hline \hline & \multicolumn{7}{c}{ Average densities $\left(\times 10^{14} \mathrm{~m}^{-3}\right)$} \\
\cline { 2 - 8 } Species & $\mathrm{H}$ & $\mathrm{C}_{2} \mathrm{H}_{5}$ & $\mathrm{C}_{2} \mathrm{H}_{3}$ & $\mathrm{CH}_{2} \mathrm{NH}$ & $\mathrm{NH}$ & $\mathrm{NH}_{2}$ & $\mathrm{e}^{-}$ & $\mathrm{C}_{3} \mathrm{H}_{7} \mathrm{~N}^{+}$ \\
\hline$A^{\prime}$ volume & 309 & 420 & 255 & 378 & 18.6 & 20.2 & 4.35 & 4.50 \\
$B^{\prime}$ volume & 265 & 330 & 192 & 289 & 13.8 & 14.8 & 1.73 & 1.95 \\
\hline \hline
\end{tabular}

The radicals are produced in different proportions inside the reactor, the most produced being $\mathrm{CH}_{2} \mathrm{NH}$ and $\mathrm{C}_{2} \mathrm{H}_{5}$, while $\mathrm{NH}$ and $\mathrm{NH}_{2}$ are generated in significantly lower quantities. For example, the average density of $\mathrm{CH}_{2} \mathrm{NH}$ radicals is more than 22 times higher than the one of $\mathrm{NH}$ radicals, for both volumes considered. Another notable feature is that the densities of the main radicals are about 100 times higher than the ones of charged species, which rapidly decrease during off times, while radical densities are barely affected by discharge pulses.

To visualize the influence of discharge pulses on the behavior of the different species and investigate in deeper details how these species contribute to the thin film growth, 2D 
absorption mappings are shown in Fig. 9. Displayed data are averaged over the different ON and OFF times of the two last periods $(1050-1190 \mu \mathrm{s})$. More precisely, $\mathrm{T}_{1-\mathrm{ON}}$ stands for absorption values averaged over the first ON time (negative drum) of the two last periods, namely during 1050-1060 and 1120-1130 $\mu$ s. Similarly, T1-OFF stands for absorption values averaged over the first OFF times (1060-1085 and 1130-1155 $\mu \mathrm{s}), \mathrm{T}_{2-\mathrm{ON}}$ stands for absorption values averaged over 1085-1095 and 1155-1165 $\mu$ s (second ON time with negative drum), and $\mathrm{T}_{2-\mathrm{OFF}}$ over $1095-1120$ and $1165-1190 \mu \mathrm{s}$. The different mappings correspond to the unrolled drum surface, with the 0 position on the $\mathrm{x}$-axis relating to the leftmost position of the drum in the xy plane. Following this notation, sample A is located around $\mathrm{x}=56 \mathrm{~mm}$ and sample $B$ around $x=168 \mathrm{~mm}$, as indicated by the rectangles added in Fig. 9. More quantitative data are given in Fig. 10, which shows more precisely the average absorption values at positions $\mathrm{A}$ and $\mathrm{B}$. 

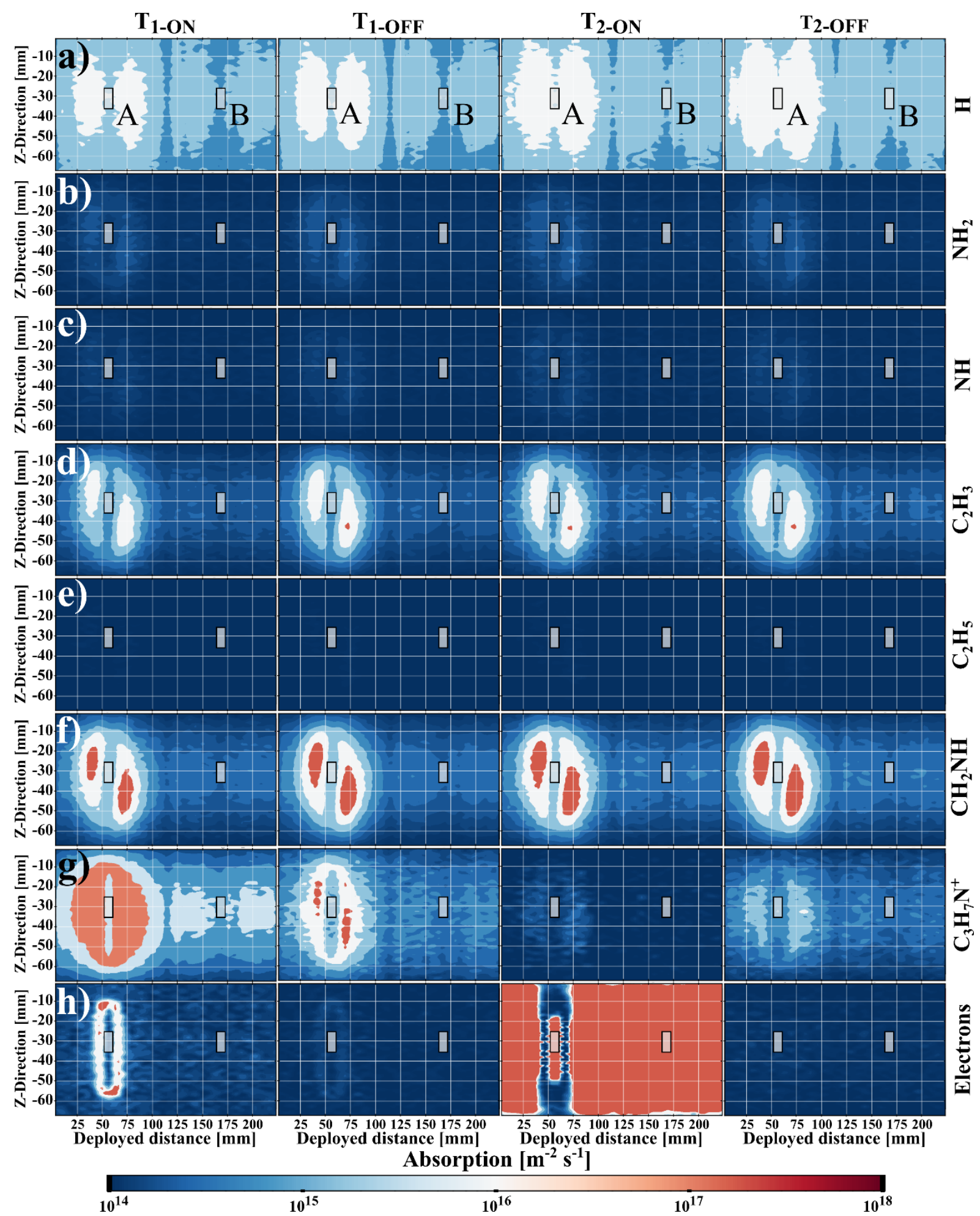

FIG. 9. 2D absorption mappings on the unrolled drum surface averaged over the different ON and OFF times of the two last periods of the plasma simulation $(1050-1190 \mu \mathrm{s})$ for (a) $\mathrm{H}$ radicals, (b) $\mathrm{NH}_{2}$ radicals, (c) $\mathrm{NH}$ radicals, (d) $\mathrm{C}_{2} \mathrm{H}_{3}$ radicals, (e) $\mathrm{C}_{2} \mathrm{H}_{5}$ radicals, (f) $\mathrm{CH}_{2} \mathrm{NH}$ radicals, (g) $\mathrm{C}_{3} \mathrm{H}_{7} \mathrm{~N}^{+}$ions and (h) electrons. The 0 position on the $\mathrm{x}$-axis relates to the leftmost 
position of the drum in the xy plane. The two positions $\mathrm{A}$ and $\mathrm{B}$ where $1 \times 1 \mathrm{~cm}^{2} \mathrm{Si}$ wafers have been placed for experimental investigations are indicated by small rectangles.
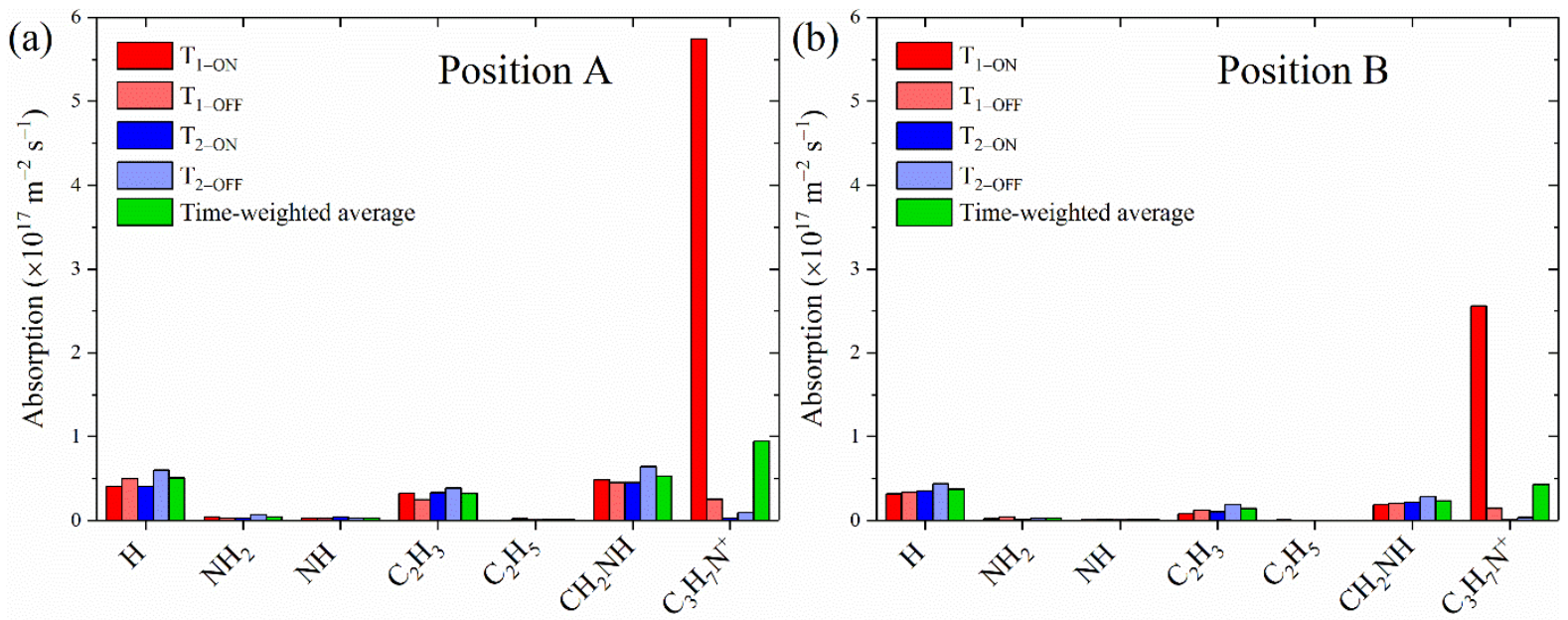

FIG. 10. Average absorption values over the different ON and OFF times of the two last periods of the plasma simulation (1050-1190 $\mu$ s), at (a) position A and (b) position B.

From Fig. 9 and FIG. 10, we see that radicals and ions mainly absorb around magnets edges (around A), and to a lower extent, at the opposite position (around B). The most absorbed radicals on the drum surface are $\mathrm{H}, \mathrm{C}_{2} \mathrm{H}_{3}$ and $\mathrm{CH}_{2} \mathrm{NH}$, while $\mathrm{NH}$ and $\mathrm{NH}_{2}$ absorb to a much lower extent. Despite its high production rate, $\mathrm{C}_{2} \mathrm{H}_{5}$ is the least absorbed radical due to its very low sticking coefficient (0.001). Conversely, despite its low sticking coefficient $(0.01), \mathrm{H}$ is highly absorbed at both positions due to its high density and probably higher mobility.

Additionally, while radicals are almost insensitive to discharges pulses, charged species strongly depend on the drum polarity. Indeed, radicals absorb on the drum surface in similar extents during ON and OFF times, whatever the polarity, because OFF times are too short for radicals to relax significantly between two ON times. Moreover, radicals motion is not influenced by the applied electric field. On the contrary, $\mathrm{C}_{3} \mathrm{H}_{7} \mathrm{~N}^{+}$ion absorption mainly occurs 
during ON times with negative drum. During these periods, the average absorption values of $\mathrm{C}_{3} \mathrm{H}_{7} \mathrm{~N}^{+}$ions are about 10 times higher than the one of the main radicals.

To better compare the relative contributions of ions and radicals to the PPF growth, time-weighted average absorption values are also indicated in Fig. 10. For both positions, these values are strongly reduced compared with those during negatively-polarized drum periods, but they are still higher than the ones of radicals, indicating that ions strongly contribute to the mass deposited.

An interesting observation is that average absoption rates of $\mathrm{C}_{2} \mathrm{H}_{3}$ radicals, $\mathrm{CH}_{2} \mathrm{NH}$ radicals and $\mathrm{C}_{3} \mathrm{H}_{7} \mathrm{~N}^{+}$ions (namely, three of the most absorbed species) are respectively 2.33, 2.26 and 2.21 times higher at position A than at position B. These values are very close to the ratio between the experimental deposition rates measured at positions $\mathrm{A}$ and $\mathrm{B}$, namely 2.57 . Conversely, the absorption rate of $\mathrm{H}$ radical (one of the two most absorbed radicals) is only 1.33 times higher at position $\mathrm{A}$ than at position $\mathrm{B}$, but this species is not expected to contribute significantly to the mass deposited. Nevertheless, a second interesting point is that this ratio is close to the one between the $[\mathrm{H}] /[\mathrm{C}]$ ratio at position $\mathrm{B}(34.7 / 50.5=0.687)$ and the $[\mathrm{H}] /[\mathrm{C}]$ ratio at position A $(27.7 / 56.9=0.487)$ determined by IBA (cf. Table 8$)$, namely $0.687 / 0.487$ $=1.41$, although the trend goes in the opposite direction.

\section{Discussion}

The plasmas generated in the cylindrical magnetron reactor described in this study are highly nonuniform due to the presence of strong magnetic field gradients. As seen in our previous study ${ }^{55}$ and in the present work, these gradients are responsible for spatial variations in plasma parameters, such as electron density and temperature, ion density and energy, radical density and distribution, and absorption rates. 
Therefore, the PPFs produced from depositing organic vapors exhibit strong changes in their properties depending on the position considered on the drum surface. In this work, we considered two different positions A and B, near magnets and at the opposite position, indicated in Fig. 1, where the magnetic field has respectively its highest and lowest values. We used complementary analytical techniques among profilometry, SEM, XPS, TOFSIMS/PCA, and IBA, to study the properties of thin films deposited from CPA in a pulsed bipolar discharge. We showed that besides the deposition rates 2.57 times higher near magnets, the PPF deposited at position A exhibit a different morphology and chemistry.

More precisely, PPFs deposited in the high magnetic field region show important delaminations (Fig. 3), a lower nitrogen incorporation (Table 6), a higher percentage of multiple $\mathrm{CN}$ bonds, such as nitrile groups, at the expense of amine functionalities (Fig. 4 and Table 7), a lower hydrogen content (Fig. 6), a higher degree of cross-linking, and a thin film density about $20 \%$ higher. We suspected that the main reason for such a different behavior was the more energetic conditions at position A, with notably a higher precursor fragmentation and a higher ion bombardment enhanced by the stronger magnetic field. Indeed, a higher fragmentation could lead to a greater number of thin film-forming species, explaining the higher deposition rates, but also to smaller depositing fragments, resulting in a denser and less flexible coating, less suited to counteracts stresses at the interface. Internal stresses in the coating could be magnified by a more intense ion bombardment, providing more energy to dissipate, as well as a greater thermal expansion mismatch caused by a stronger substrate heating. Additionally, the higher ion bombardment could break more chemical bonds on the growing film surface, releasing hydrogen and nitrogen atoms in the gas phase, and generating more dangling bonds, accelerating the deposition rates and increasing the degree of crosslinking and the number of multiple bonds, as also observed in previous studies..$^{32,33,104}$ 
To confirm these hypotheses and better understand the plasma polymerization mechanisms in this particular reactor configuration, we performed 3D PIC-MC simulations of a CPA discharge in the cylindrical magnetron reactor. Due to the huge number of reactions occurring in a plasma polymerization process from a molecule as complex as CPA, several considerations and approximations were made to enable the use of the 3D PIC-MC tool to extract information about thin film growth mechanisms. Indeed, take into account all possible physicochemical processes (numerous collisions leading to various fragmentation pathways, to the ionization and rotational, vibrational, electronic transitions of the CPA molecule and its fragments, emission of energetic photons able to intervene in subsequent processes, chemical reactions occurring between all generated species, both in gas phase and on reactor walls, surface processes such as adsorption, diffusion, secondary electron emission, reactive etching, sputtering or ion implantation) would require unrealistic numerical resources and computing times.

Therefore, we decided to perform two simulation runs. The first one aimed at studying the behavior of the CPA ion (supposed to be the majority ion due to the abundance of CPA molecules compared to other species and to the relatively low ionization energy of the CPA molecule) and determining the main radicals produced in the discharge in power conditions as close as possible from the one used experimentally. The goal of the second run was to study the diffusion and absorption on reactor walls of the main species. As substrate heating and deposited material was assumed negligible on computing timescale involved (1.2 ms), constant sticking coefficients (taken from the literature) were considered. This modus operando enabled to confirm experimental assumptions and to provide inputs for discussion regarding plasma polymerization processes.

Indeed, numerical results showed that ion density is 2.3 to 2.5 times higher in the vicinity of position A compared to position B (Table 9), due to the higher electron density that 
leads to higher ionization rates. Moreover, ions reaching position A are $35 \%$ more energetic than ions reaching B (Fig. 7). This clearly supports the stronger ion bombardment near magnets previously discussed. The distribution of radicals in the reactor is more homogeneous than the one of charged species (Table 9), because they are insensitive to the discharge pulses and polarity. However, their production is spatially dependent on electron distribution (Fig. 8).

We showed that the main radicals produced in the CPA discharge are $\mathrm{H}, \mathrm{CH}_{2} \mathrm{NH}, \mathrm{C}_{2} \mathrm{H}_{3}$ and $\mathrm{C}_{2} \mathrm{H}_{5}$. $\mathrm{NH}$ and $\mathrm{NH}_{2}$ radicals, which were expected to contribute significantly to surface functionalization, are produced to a much lower extent (Fig. 8), leading to very low absorption rates (Fig. 9 and Fig. 10). Nevertheless, the abundance of certain radicals does not necessarily mean that they play an important role in the PPF growth. For example, $\mathrm{C}_{2} \mathrm{H}_{5}$ is the main species formed in the discharge, but its absorption rate is paltry due to its very low sticking coefficient.

An important result is that the ratios between the absorption rates of the most absorbing species $\left(\mathrm{CH}_{2} \mathrm{NH}, \mathrm{C}_{2} \mathrm{H}_{3}, \mathrm{C}_{3} \mathrm{H}_{7} \mathrm{~N}^{+}\right)$at position $\mathrm{A}$ and the ones at position $\mathrm{B}$ (between 2.21 and 2.33) are very close to the ratio between the deposition rates experimentally measured at the same positions (2.57) (Fig. 10). This indicates that absorption rates are important data to determine the species actively taking part to the thin film growth. For $\mathrm{H}$ radicals, the ratio between absorption rates at position A and at position B is only 1.33 (Fig. 10), but hydrogen is not suspected to contribute significantly to the mass deposited. Interestingly, this ratio is very close to the inverse of the ratio between the $[\mathrm{H}] /[\mathrm{C}]$ ratio measured by IBA at position $\mathrm{A}$ and the $[\mathrm{H}] /[\mathrm{C}]$ ratio measured at position $\mathrm{B}$, namely $0.487 / 0.687=1 / 1.41$ (Table 8 ). This could indicate that, instead of contributing to the thin film growth, atomic hydrogen adsorbed on the growing film could be responsible for hydrogen abstraction from the PPF, by generating molecular dihydrogen released in the gas phase, following an Eley-Rideal mechanism. ${ }^{105,106}$

The lower $[\mathrm{N}] /[\mathrm{C}]$ ratio at position A compared with position B could possibly be explained by a similar process, or also following a Langmuir-Hinshelwood mechanism 
(migration of two adsorbed atoms on the surface followed by the formation of a molecule that desorbs in the gas phase), ${ }^{105}$ which could be enhanced at position $\mathrm{A}$ by the stronger ion bombardment that brings more energy and magnifies surface diffusion. Another explanation could be a greater fragmentation of the CPA molecule in the volume adjacent to position A due to the higher electron density near magnets, leading to a lower retention of $\mathrm{CN}$ bonds. Indeed, it was previously shown that the presence of $\mathrm{CN}$ bonds in the precursor (or depositing fragments) was important for a greater nitrogen incorporation. ${ }^{32,33}$ Nevertheless, the results presented in this work do not enable to support this hypothesis, because the two species retaining the $\mathrm{CN}$ bond among tracked species $\left(\mathrm{CH}_{2} \mathrm{NH}\right.$ and $\left.\mathrm{C}_{3} \mathrm{H}_{7} \mathrm{~N}^{+}\right)$stay more abundant near position A than near position B.

The most interesting point of the present work is that it allows to discuss the respective roles of ions and radicals in PPF growth mechanisms, roles that are actively debated in the literature..$^{4,716}$ Indeed, our results confirm that even if the ion density in the gas phase is about 100 times lower than the density of the main radicals (Table 9), adsorption of ionic species on the growing PPF can be up to 10 times higher than radicals adsorption when they are accelerated toward the surface (Fig. 10). Nevertheless, ions are very sensitive to discharge pulses and polarity and their role is significantly reduced during OFF times because they are rapidly neutralized (Fig. 9). Conversely, radicals consistently take part to the thin film growth throughout the process duration. Consequently, the respective roles of ions and radicals toward a plasma polymerization process strongly depends on the reactor geometry and on the applied signal parameters.

\section{Conclusions}

In this study, we performed a combined experimental and numerical study of a cyclopropylamine plasma in a low-pressure cylindrical magnetron reactor. We showed that the 
magnetic field strength strongly influences the final PPF properties, such as deposition rates, adherence, roughness, density, and degrees of functionalization and cross-linking.

To investigate plasma polymerization mechanisms, we performed for the first time 3D PIC-MC simulations of the CPA discharge after computing electron-cyclopropylamine collision cross sections using the R-matrix method. Due to the complexity of the plasma polymerization process and the computational times and resources required for 3D PIC-MC numerical study, several assumptions and simplifications have been done to perform the simulations on a feasible timescale. Nevertheless, the presented results enabled to determine the main radicals formed in the discharge and visualize their spatial distribution, to assess the energy of ions impacting the substrate, to correlate the numerically calculated absorption rates with experimentally measured deposition rates, and to investigate the contribution of ions and radicals toward thin film growth. We showed that despite their strongly different production rates, both ions and radicals significantly contribute to the mass deposited, but their respective roles are strongly dependent on the reactor geometry and discharge parameters.

Therefore, we showed that 3D PIC-MC simulations are a powerful tool to bring new insight into plasma polymerization mechanisms and to possibly quantify phenomena in reactor configurations where measurements are difficult to perform.

\section{Acknowledgements}

The authors gratefully acknowledge the financial support of the Walloon region under the Flycoat project, $\mathrm{N}^{\circ} 1318147$. For all simulations, computational resources were provided by the Consortium des Équipements de Calcul Intensif (CÉCI), funded by the Fonds de la Recherche Scientifique de Belgique (F.R.S.-FNRS) under Grant $\mathrm{N}^{\circ}$ 2.5020.11. The authors would like to thank Dan Graham, Ph.D., for developing the NESAC/BIO Toolbox used in this study and the NIH grant EB-002027 for supporting the toolbox development. The authors also 
thank Céline Noel and Alexandre Felten for their assistance in the TOF-SIMS experiments and Paul-Louis Debarsy and Julien Colaux for their assistance in performing IBA experiments. The authors also acknowledge the SIAM platform of the University of Namur.

\section{References}

${ }^{1}$ A. Choukourov, H. Biederman, D. Slavinska, L. Hanley, A. Grinevich, H. Boldyryeva, and A. Mackova, J. Phys. Chem. B 109, 23086 (2005).

${ }^{2}$ H. J. Griesser, R. C. Chatelier, T. R. Gengenbach, G. Johnson, and J. G. Steele, J. Biomater. Sci., Polym. Ed. 5, 531 (1994).

${ }^{3}$ K. S. Siow, L. Britcher, S. Kumar, and H. J. Griesser, Plasma Process. Polym. 3, 392 (2006).

${ }^{4}$ F. Khelifa, S. Ershov, Y. Habibi, R. Snyders, and P. Dubois, Chem. Rev. 116, 3975 (2016).

${ }^{5}$ D. Cossement, F. Renaux, D. Thiry, S. Ligot, R. Francq, and R. Snyders, Appl. Surf. Sci. 355, $842(2015)$.

${ }^{6}$ J. Dorst, M. Vandenbossche, M. Amberg, L. Bernard, P. Rupper, K. D. Weltmann, K. Fricke, and D. Hegemann, Langmuir 33, 10736 (2017).

${ }^{7}$ D. Thiry, S. Konstantinidis, J. Cornil, and R. Snyders, Thin Solid Films 606, 19 (2016).

${ }^{8}$ S.-H. Seo, J.-H. In, and H.-Y. Chang, Plasma Sources Sci. Technol. 13, 409 (2004).

${ }^{9}$ S.-H. Seo, J.-H. In, H.-Y. Chang, and J.-G. Han, J. Appl. Phys. 98 (2005).

${ }^{10}$ P. Sigurjonsson and J. T. Gudmundsson, J. Phys.: Conf. Ser. 100 (2008).

${ }^{11}$ M. Shen and A. T. Bell, A Review of Recent Advances in Plasma Polymerization, in Plasma Polymerization (AMERICAN CHEMICAL SOCIETY, 1979), Vol. 108, pp. 1.

${ }^{12}$ H. Yasuda, Plasma polymerization (Academic Press, Orlando, 1985).

${ }^{13}$ R. d'Agostino, Plasma Deposition, Treatment, and Etching of Polymers (Academic Press, San Diego, CA, 1990).

${ }^{14}$ A. Michelmore, P. Gross-Kosche, S. A. Al-Bataineh, J. D. Whittle, and R. D. Short, Langmuir 29, 2595 (2013).

${ }^{15}$ A. J. Beck, S. Candan, R. D. Short, A. Goodyear, and N. S. J. Braithwaite, J. Phys. Chem. B 105, 5730 (2001).

${ }^{16}$ A. Michelmore, J. D. Whittle, and R. D. Short, Frontiers in Physics 3 (2015).

${ }^{17}$ M. Mao and A. Bogaerts, J. Phys. D: Appl. Phys. 43, 205201 (2010).

${ }^{18}$ S. Candan, A. J. Beck, L. O'Toole, R. D. Short, A. Goodyear, and N. St J. Braithwaite, Phys. Chem. Chem. Phys. 1, 3117 (1999).

${ }^{19}$ D. B. Haddow, R. M. France, R. D. Short, J. W. Bradley, and D. Barton, Langmuir 16, 5654 (2000).

${ }^{20}$ A. Michelmore, D. A. Steele, D. E. Robinson, J. D. Whittle, and R. D. Short, Soft Matter 9, 6167 (2013).

${ }^{21}$ D. Hegemann, E. Körner, N. Blanchard, M. Drabik, and S. Guimond, Appl. Phys. Lett. 101, 211603 (2012).

${ }^{22}$ C. Rigaux, F. Tichelaar, P. Louette, J. L. Colaux, and S. Lucas, Surf. Coat. Technol. 205, S601 (2011).

${ }^{23}$ S. Mathioudaki, B. Barthélémy, S. Detriche, C. Vandenabeele, J. Delhalle, Z. Mekhalif, and S. Lucas, ACS Appl. Nano Mater. 1, 3464 (2018).

${ }^{24}$ L. Denis, P. Marsal, Y. Olivier, T. Godfroid, R. Lazzaroni, M. Hecq, J. Cornil, and R. Snyders, Plasma Process. Polym. 7, 172 (2010). 
${ }^{25}$ A. Manakhov, L. Zajíčková, M. Eliáš, J. Čechal, J. Polčák, J. Hnilica, Š. Bittnerová, and D. Nečas, Plasma Process. Polym. 11, 532 (2014).

${ }^{26}$ A. Manakhov, P. Skládal, D. Nečas, J. Čechal, J. Polčák, M. Eliáš, and L. Zajíčková, physica status solidi (a) 211, 2801 (2014).

${ }^{27}$ A. Manakhov, D. Nečas, J. Čechal, D. Pavliňák, M. Eliáš, and L. Zajíčková, Thin Solid Films 581, 7 (2015).

${ }^{28}$ A. Manakhov, E. Makhneva, P. Skládal, D. Nečas, J. Čechal, L. Kalina, M. Eliáš, and L. Zajíčková, Appl. Surf. Sci. 360, 28 (2016).

${ }^{29}$ E. Makhneva, A. Manakhov, P. Skládal, and L. Zajíčková, Surf. Coat. Technol. 290, 116 (2016).

${ }^{30}$ L. Štrbková, A. Manakhov, L. Zajíčková, A. Stoica, P. Veselý, and R. Chmelík, Surf. Coat. Technol. 295, 70 (2016).

${ }^{31}$ A. Manakhov, M. Landová, J. Medalová, M. Michlíček, J. Polčák, D. Nečas, and L. Zajíčková, Plasma Process. Polym. 14, 1600123 (2017).

${ }^{32}$ C. Vandenabeele, M. Buddhadasa, P.-L. Girard-Lauriault, and R. Snyders, Thin Solid Films 630, 100 (2017).

${ }^{33}$ M. Buddhadasa, C. R. Vandenabeele, R. Snyders, and P.-L. Girard-Lauriault, Plasma Process. Polym. 14, 1700030 (2017).

${ }^{34}$ W. Z. Collison, T. Q. Ni, and M. S. Barnes, J. Vac. Sci. Technol., A 16, 100 (1998).

${ }^{35}$ C. S. Corr, E. Despiau-Pujo, P. Chabert, W. G. Graham, F. G. Marro, and D. B. Graves, J. Phys. D: Appl. Phys. 41, 185202 (2008).

${ }^{36}$ A. Hurlbatt, A. R. Gibson, S. Schröter, J. Bredin, A. P. S. Foote, P. Grondein, D. O'Connell, and T. Gans, Plasma Process. Polym. 14, 1600138 (2017).

${ }^{37}$ A. Bogaerts, E. Bultinck, M. Eckert, V. Georgieva, M. Mao, E. Neyts, and L. Schwaederlé, Plasma Process. Polym. 6, 295 (2009).

${ }^{38}$ S. Stoykov, C. Eggs, and U. Kortshagen, J. Phys. D: Appl. Phys. 34, 2160 (2001).

${ }^{39}$ M. Mao, J. Benedikt, A. Consoli, and A. Bogaerts, J. Phys. D: Appl. Phys. 41, 225201 (2008).

${ }^{40}$ Y. Miyagawa, H. Nakadate, M. Tanaka, M. Ikeyama, S. Nakao, and S. Miyagawa, Surf. Coat. Technol. 201, 8414 (2007).

${ }^{41}$ D. A. Ariskin, I. V. Schweigert, A. L. Alexandrov, A. Bogaerts, and F. M. Peeters, J. Appl. Phys. 105, 063305 (2009).

${ }^{42}$ K. Ostrikov, H.-J. Yoon, A. E. Rider, and S. V. Vladimirov, Plasma Process. Polym. 4, 27 (2007).

${ }^{43}$ V. N. Volynets, A. V. Lukyanova, A. T. Rakhimov, D. I. Slovetsky, and N. V. Suetin, J. Phys. D: Appl. Phys. 26, 647 (1993).

${ }^{44}$ E. Gogolides, M. Stathakopoulos, and A. Boudouvis, J. Phys. D: Appl. Phys. 27, 1878 (1994).

${ }^{45}$ Y.-R. Zhang, S. Tinck, P. D. Schepper, Y.-N. Wang, and A. Bogaerts, J. Vac. Sci. Technol., A 33, 021310 (2015).

${ }^{46}$ A. L. Alexandrov and I. V. Schweigert, Plasma Sources Sci. Technol. 14, 209 (2005).

${ }^{47}$ H. C. Thejaswini, S. Peglow, U. Martens, V. Sushkov, and R. Hippler, Contrib. Plasma Phys. 54, 683 (2014).

${ }^{48}$ S.-X. Zhao, Y.-R. Zhang, F. Gao, Y.-N. Wang, and A. Bogaerts, J. Appl. Phys. 117, 243303 (2015).

${ }^{49}$ H. C. Kim, F. Iza, S. S. Yang, M. Radmilović-Radjenović, and J. K. Lee, J. Phys. D: Appl. Phys. 38, R283 (2005).

${ }^{50}$ D. J. Economou, Plasma Process. Polym. 14, 1600152 (2017).

${ }^{51}$ C. K. Birdsall and A. B. Langdon, Plasma Physics via Computer Simulation (Taylor \& Francis, 2005).

${ }^{52}$ D. Tskhakaya, K. Matyash, R. Schneider, and F. Taccogna, Contrib. Plasma Phys. 47, 563 (2007). 
${ }^{53}$ G. A. Bird, Molecular Gas Dynamics and the Direct Simulation of Gas Flows (Clarendon Press, Oxford, 1994).

${ }^{54}$ C. Schwanke, A. Pflug, M. Siemers, and B. Szyszka, Parallel Particle-in-Cell Monte-Carlo Algorithm for Simulation of Gas Discharges under PVM and MPI, in Lecture Notes in Computer Science, edited by K. Jónasson (Springer, Berlin, 2010), Vol. 7133, pp. 213.

${ }^{55}$ S. Mathioudaki, C. Vandenabeele, R. Tonneau, A. Pflug, and S. Lucas, J. Vac. Sci. Technol., A 37, 031301 (2019).

${ }^{56}$ J. Tennyson, Physics Reports 491, 29 (2010).

${ }^{57}$ C. R. Vandenabeele and S. Lucas, Mater. Sci. Eng., R 139, 100521 (2020).

${ }^{58}$ D. Graham, (National Institute for Biomedical Imaging and Bioengineering).

${ }^{59}$ J. E. Jackson, A User's Guide to Principal Components (Wiley, 2005).

${ }^{60}$ D. J. Graham and B. D. Ratner, Langmuir 18, 5861 (2002).

${ }^{61}$ C. Jeynes, N. P. Barradas, P. K. Marriott, G. Boudreault, M. Jenkin, E. Wendler, and R. P. Webb, J. Phys. D: Appl. Phys. 36, R97 (2003).

${ }^{62}$ A. F. Gurbich, Nuclear Instruments and Methods in Physics Research Section B: Beam Interactions with Materials and Atoms 371, 27 (2016).

${ }^{63}$ Y.-K. Kim and M. E. Rudd, Physical Review A 50, 3954 (1994).

${ }^{64}$ N. F. Mott and R. H. Fowler, Proceedings of the Royal Society of London. Series A, Containing Papers of a Mathematical and Physical Character 126, 259 (1930).

${ }^{65}$ H. Bethe, Annalen der Physik 397, 325 (1930).

${ }^{66}$ H.-J. Werner, P. J. Knowles, G. Knizia, F. R. Manby, and M. Schütz, Wiley Interdisciplinary Reviews: Computational Molecular Science 2, 242 (2012).

${ }^{67}$ M.-Y. Song, J.-S. Yoon, H. Cho, Y. Itikawa, G. P. Karwasz, V. Kokoouline, Y. Nakamura, and J. Tennyson, J. Phys. Chem. Ref. Data 44, 023101 (2015).

${ }^{68}$ M.-Y. Song, J.-S. Yoon, H. Cho, G. P. Karwasz, V. Kokoouline, Y. Nakamura, and J. Tennyson, J. Phys. Chem. Ref. Data 46, 013106 (2017).

${ }^{69}$ J. R. Hamilton, J. Tennyson, S. Huang, and M. J. Kushner, Plasma Sources Sci. Technol. 26, 065010 (2017).

${ }^{70}$ D. D. Wagman, W. H. Evans, V. B. Parker, I. Halow, S. M. Bailey, and R. H. Schumm, "Selected Values of Chemical Thermodynamic Properties. Tables for the First ThirtyFour Elements in the Standard Order of Arrangement," Institute for Basic Standards. National Bureau of Standards, Washington, D.C. (1968).

${ }^{71}$ D. D. Wagman, W. H. Evans, V. B. Parker, I. Halow, S. M. Bailey, and R. H. Schumm, "Selected Values of Chemical Thermodynamic Properties. Tables for Elements 35-53 in the Standard Order of Arrangement," Institute for Basic Standards. National Bureau of Standards, Washington, D.C. (1969).

${ }^{72}$ V. H. Dibeler and S. K. Liston, J. Chem. Phys. 48, 4765 (1968).

${ }^{73}$ R. F. Pottie and F. P. Lossing, J. Am. Chem. Soc. 85, 269 (1963).

${ }^{74}$ J. A. Kerr, Chem. Rev. 66, 465 (1966).

${ }^{75}$ Y.-R. Luo, Bond Dissociation Energies, in CRC handbook of chemistry and physics, 89th edition, edited by D. R. Lide (CRC Press/Taylor and Francis, Boca Raton, FL, 2009).

${ }^{76}$ W. D. Good and R. T. Moore, The Journal of Chemical Thermodynamics 3, 701 (1971).

${ }^{77}$ T. L. Cottrell, The strength of chemical bonds (Butterworths, London, 1954).

${ }^{78}$ S. W. Benson, J. Chem. Educ. 42, 502 (1965).

${ }^{79}$ L. Brewer, W. T. Hicks, and O. H. Krikorian, J. Chem. Phys. 36, 182 (1962).

${ }^{80} \mathrm{~V}$. I. Vedeneev, Bond energies, ionization potentials and electron affinities (St. Martin's Press, New York, 1966), p.202 p.

${ }^{81}$ P. G. Burke, R-Matrix Theory of Atomic Collisions: Application to Atomic, Molecular and Optical Processes (Springer, Berlin, 2011). 
${ }^{82}$ J. M. Carr, P. G. Galiatsatos, J. D. Gorfinkiel, A. G. Harvey, M. A. Lysaght, D. Madden, Z. Mašín, M. Plummer, J. Tennyson, and H. N. Varambhia, The European Physical Journal D 66, 58 (2012).

${ }^{83}$ J. Tennyson, D. B. Brown, J. J. Munro, I. Rozum, H. N. Varambhia, and N. Vinci, J. Phys.: Conf. Ser. 86, 012001 (2007).

${ }^{84}$ W. J. Brigg, J. Tennyson, and M. Plummer, J. Phys. B: At. Mol. Opt. Phys. 47, 185203 (2014).

${ }^{85}$ N. Sanna and F. A. Gianturco, Comput. Phys. Commun. 114, 142 (1998).

${ }^{86}$ R. D. Johnson III, NIST Computational Chemistry Comparison and Benchmark DataBase, NIST Standard Reference Database Number 101 National Institute of Standards and Technology, 2018, http://cccbdb.nist.gov/

${ }^{87}$ D. K. Hendricksen and M. D. Harmony, J. Chem. Phys. 51, 700 (1969).

${ }^{88}$ A. Faure and J. Tennyson, Mon. Not. R. Astron. Soc. 325, 443 (2001).

${ }^{89}$ A. Pflug, M. Siemers, C. Schwanke, B. Febty Kurnia, V. Sittinger, and B. Szyszka, Mater. Technol. 26, 10 (2011).

${ }^{90}$ A. Pflug, M. Siemers, T. Melzig, L. Schäfer, and G. Bräuer, Surf. Coat. Technol. 260, 411 (2014).

${ }^{91}$ A. Pflug, M. Siemers, T. Melzig, D. Rademacher, T. Zickenrott, and M. Vergöhl, Surf. Coat. Technol. 241, 45 (2014).

${ }^{92}$ A. Pflug, M. Höfer, T. Harig, M. Armgardt, C. Britze, M. Siemers, T. Melzig, and L. Schäfer, Thin Solid Films 595, 266 (2015).

${ }^{93}$ C. Geuzaine and J.-F. Remacle, Int. J. Numer. Meth. Eng. 79, 1309 (2009).

${ }^{94}$ C. A. Brebbia and R. Magureanu, Eng. Anal. 4, 178 (1987).

${ }^{95}$ K. Koura and H. Matsumoto, Physics of Fluids A: Fluid Dynamics 3, 2459 (1991).

${ }^{96}$ C. Vandenabeele, R. Maurau, S. Bulou, F. Siffer, M. Gérard, T. Belmonte, and P. Choquet, Plasma Process. Polym. 11, 1089 (2014).

${ }^{97}$ M. E. Moustapha, J. F. Friedrich, Z. R. Farag, S. Krüger, G. Hidde, and M. M. Azzam, Promotion of Adhesion of Green Flame Retardant Coatings onto Polyolefins by Depositing Ultra-Thin Plasma Polymer Films, in Progress in Adhesion and Adhesives, edited by K. Mittal (John Wiley \& Sons, Hoboken, NJ, 2017), pp. 399.

${ }^{98}$ S. Zhang, X. Lam Bui, X. T. Zeng, and X. Li, Thin Solid Films 482, 138 (2005).

${ }^{99}$ R. F. Bunshah, Handbook of Deposition Technologies for Films and Coatings: Science, Technology, and Applications (Noyes Publications, 1994).

${ }^{100}$ M. Ohring, Materials Science of Thin Films (Elsevier Science, USA, 2001).

${ }^{101}$ A. V. Naumkin, A. Kraut-Vas, S. W. Gaarenstroom, and C. J. Powell, NIST X-ray Photoelectron Spectroscopy Database, Version 4.1 National Institute of Standards and Technology, 2012, https://srdata.nist.gov/xps/.

${ }^{102}$ A. Nelson, B. W. Muir, J. Oldham, C. Fong, K. M. McLean, P. G. Hartley, S. K. Øiseth, and M. James, Langmuir 22, 453 (2006).

${ }^{103}$ C. Hopf, T. Schwarz-Selinger, W. Jacob, and A. v. Keudell, J. Appl. Phys. 87, 2719 (2000).

${ }^{104}$ J. Ryssy, E. Prioste-Amaral, D. F. N. Assuncao, N. Rogers, G. T. S. Kirby, L. E. Smith, and A. Michelmore, Phys. Chem. Chem. Phys. 18, 4496 (2016).

${ }^{105}$ G. Ertl, Surf. Sci. 299-300, 742 (1994).

${ }^{106}$ W. H. Weinberg, Acc. Chem. Res. 29, 479 (1996). 


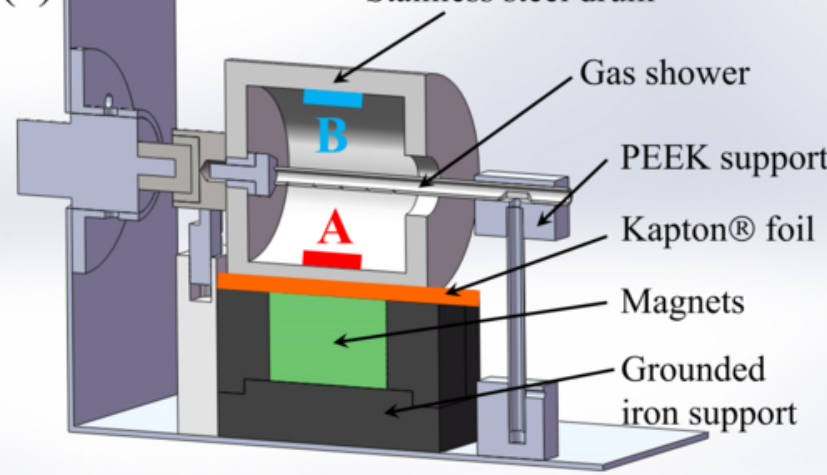

(b)

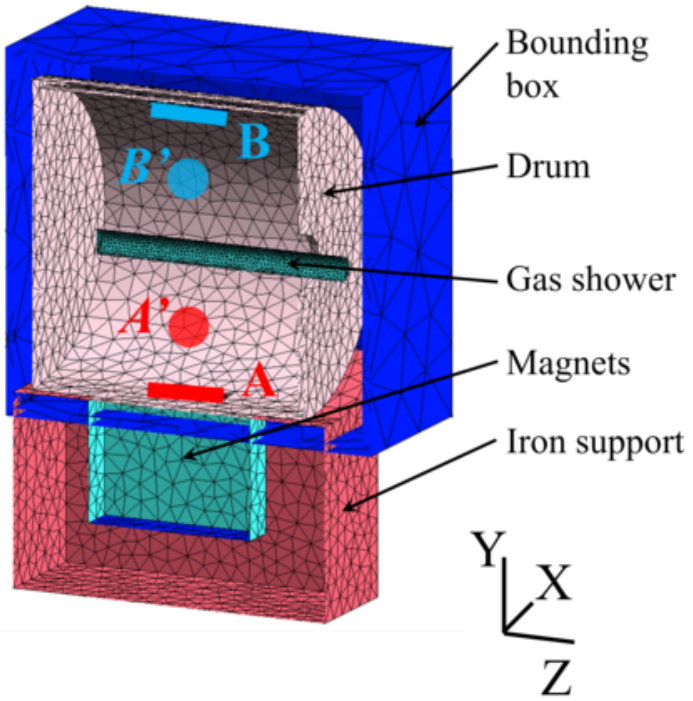




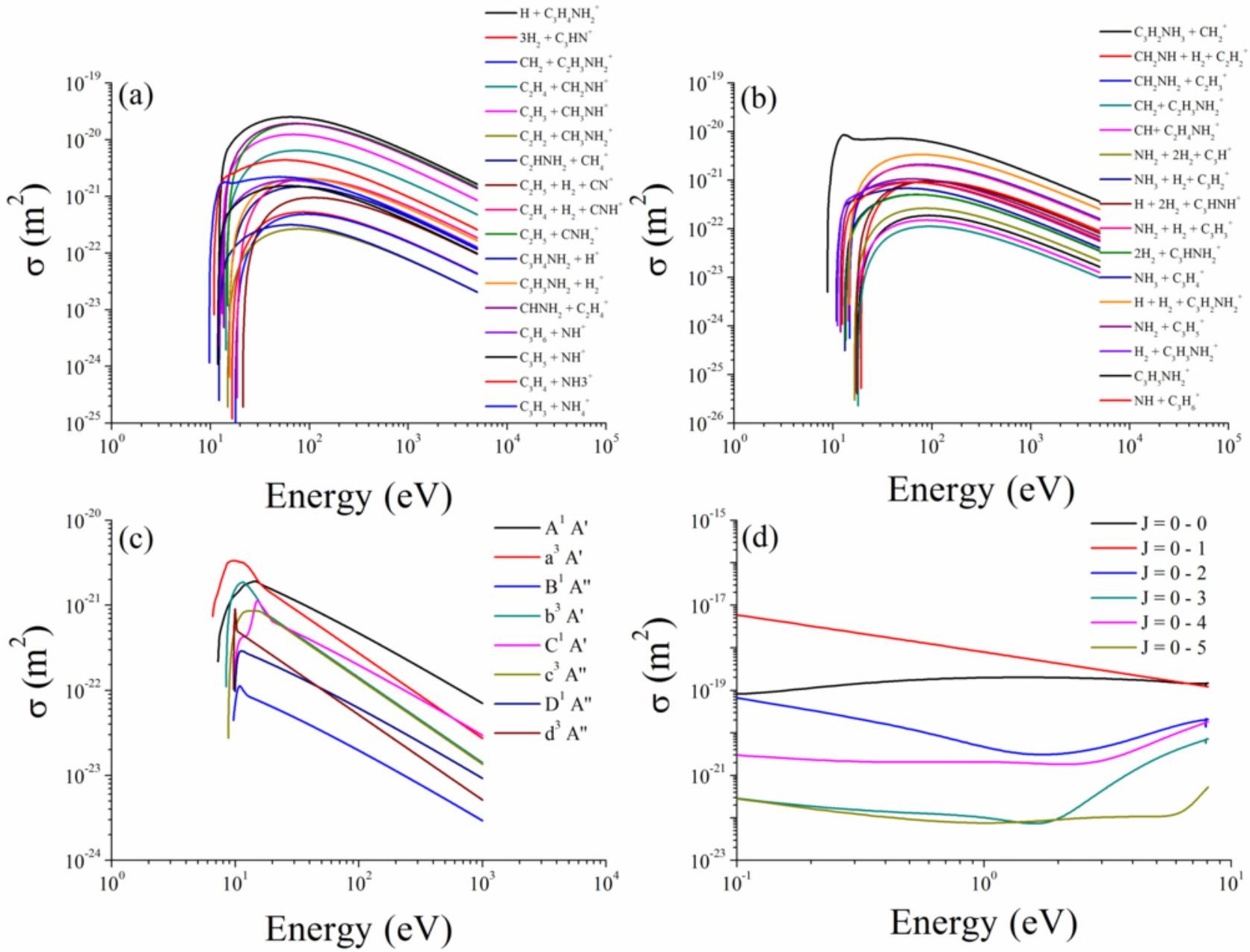




\section{Sample A}

\section{Sample B}

\section{$5 \mu \mathrm{m}$}

\section{5 쓰}

\section{Sample A}

\section{Sample B}




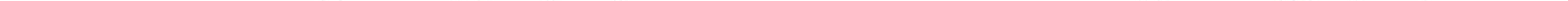



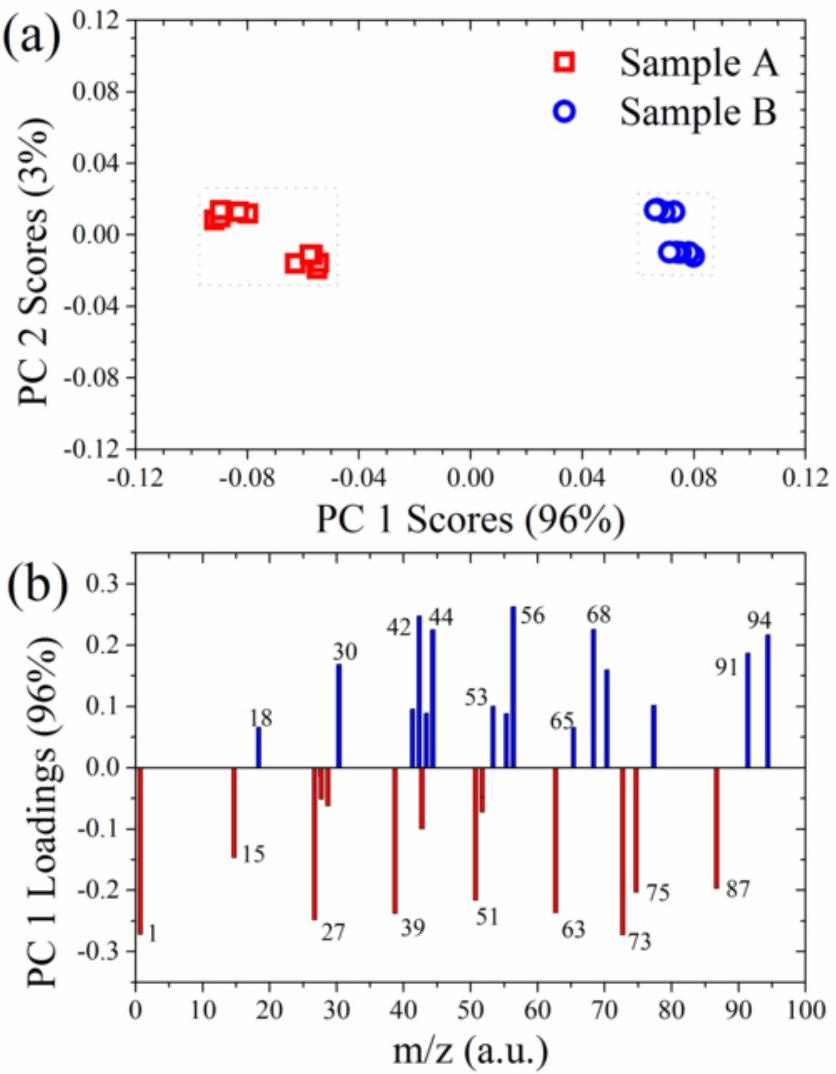


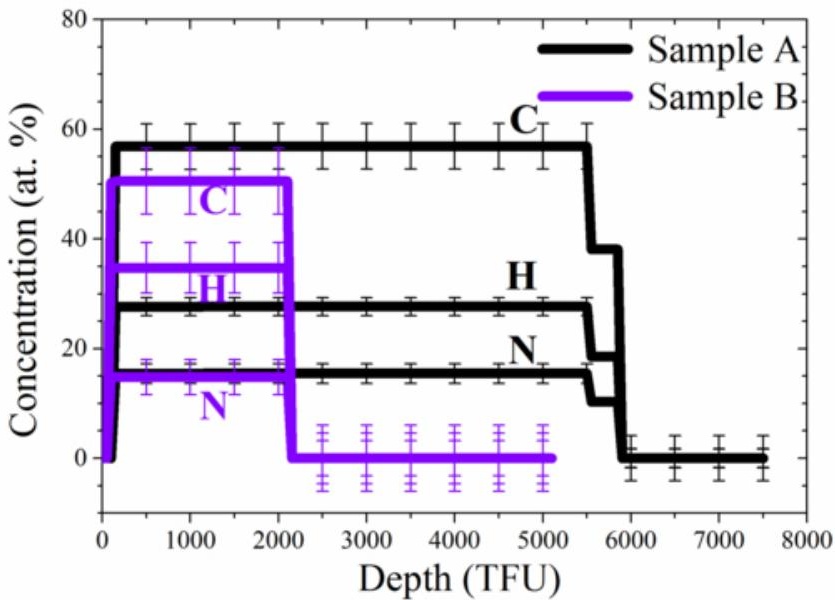



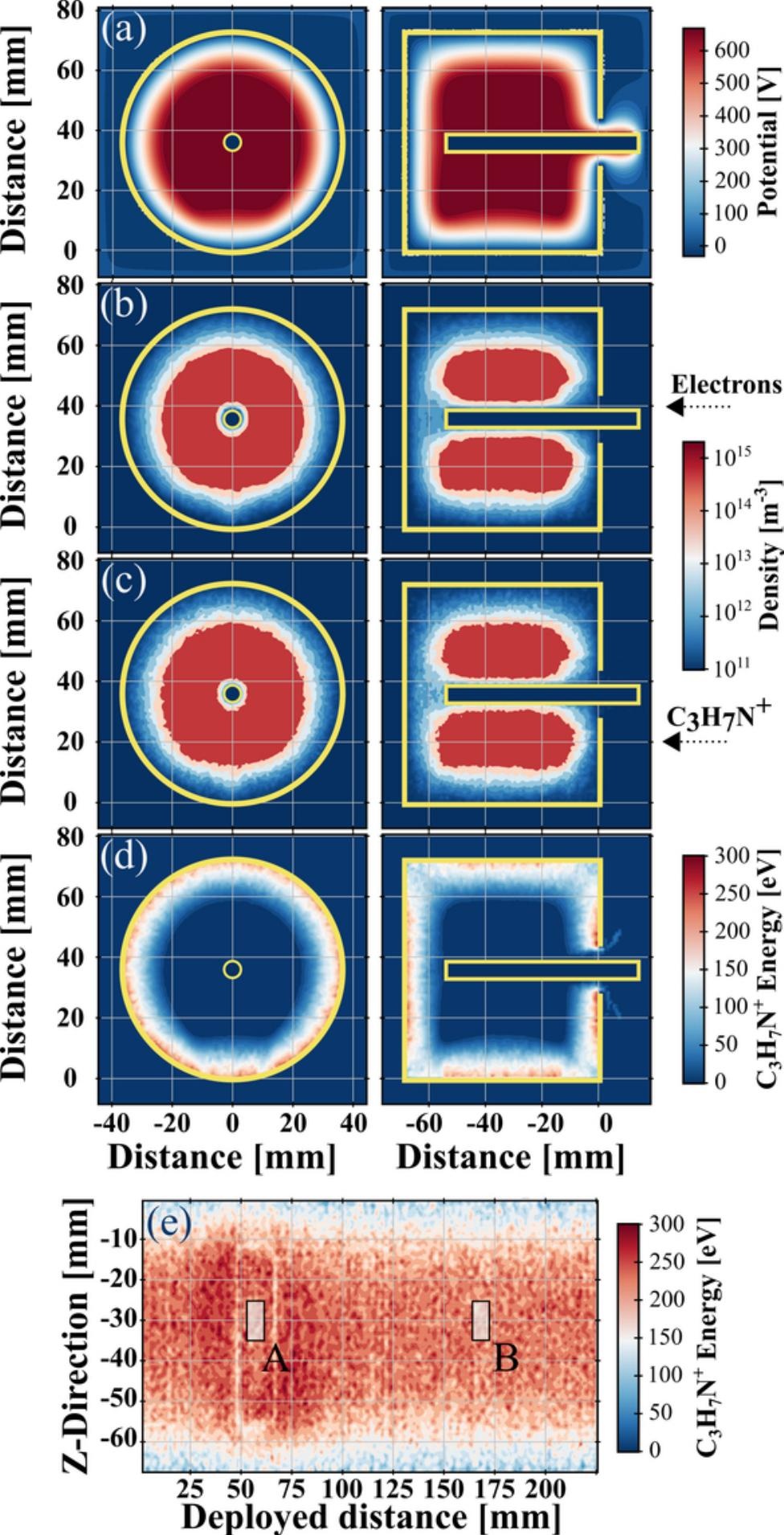
Average density $\left[\mathrm{m}^{-3}\right]$

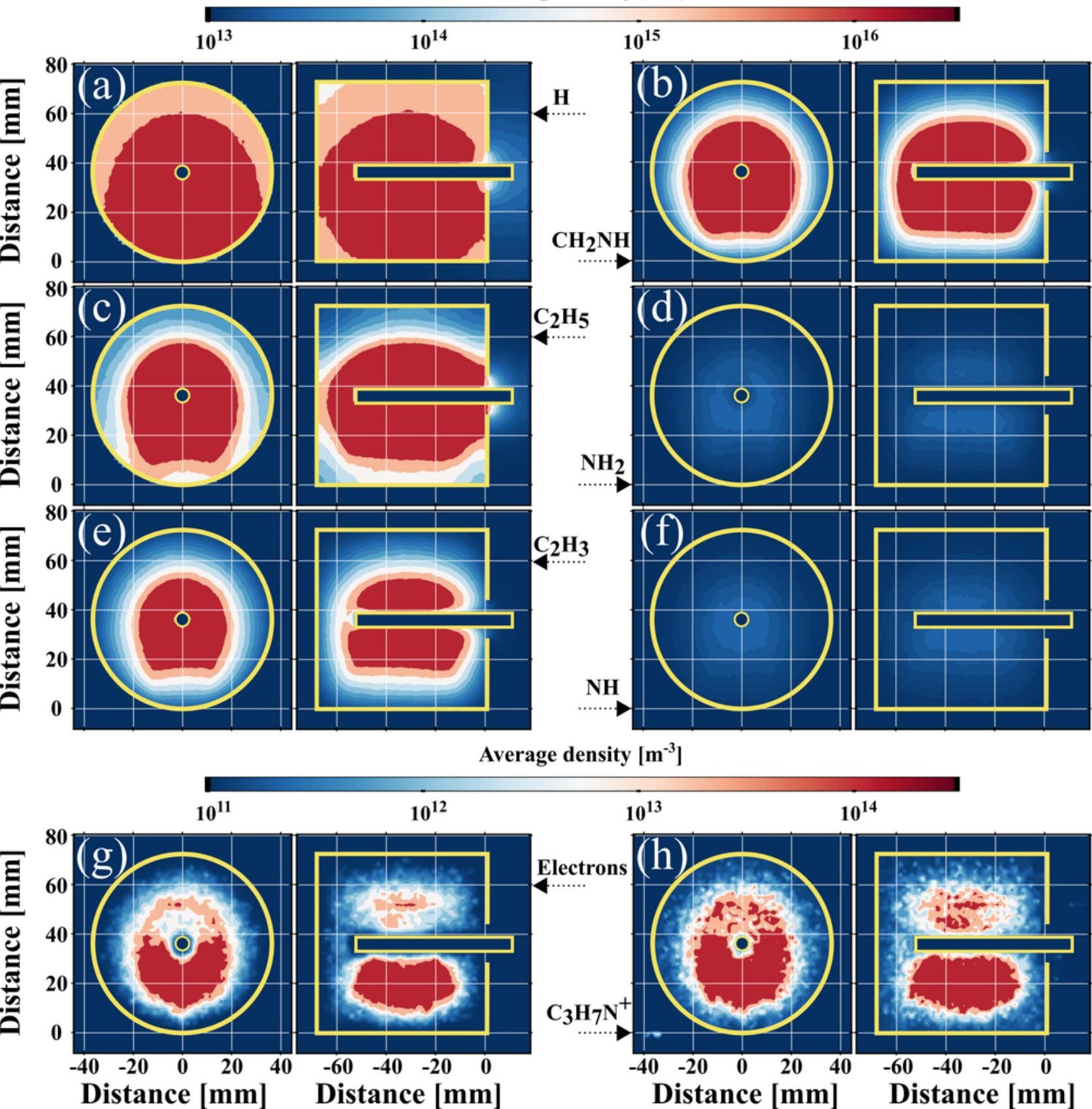


